\title{
ESTUDO NUMÉRICO DO PAPEL DOS ESQUEMAS DE CONVECÇ̃̃̃O NA SIMULAÇÃO DE UM EVENTO SEVERO NOS EXTRATRÓPICOS DO BRASIL
}

\author{
Marcelo Félix Alonso e Jaci Maria Bilhalva Saraiva² \\ Recebido em 4 dezembro, 2006 / Aceito em 6 junho, 2007 \\ Received on December 4, 2006 / Accepted on June 6, 2007
}

\begin{abstract}
A comparison study of the Kuo and Grell cumulus parameterizations schemes (CPSs), was conducted using the Brazilian Regional Modeling System (BRAMS), for to evaluate this role in severe storms simulation. In this context, we analyzed a cold front case on Brazil south region, occurred on December 11, 2003. The experiments are identical, except from the CPSs difference: the SCKU0 experiment uses the Kuo scheme and the SCGRELL experiment uses the Grell scheme. The evaluation of the simulated precipitation focuses on comparison of two aspects: Intensity and areal coverage. Also we analyzed the convective parameters simulation conceived to identify atmospheric environments favorable for the severe convection. The accumulated precipitation simulated from SCKUO underestimated the observed data, but better represented the areal coverage. The accumulated precipitation simulated from SCGRELL better represented the rain intensity, but overestimated the observed data. Therefore, the better option, for this convection case, is the Grell Parameterization. Both experiments simulated the convective parameters with good approximation, with emphasis in Grell scheme. This result showed that the mesoscale model is a useful tool in the identification of atmospheric environments favorable for the development of severe convective storms, with great CPSs contribution.
\end{abstract}

Keywords: BRAMS, convection parameterization, severe storms.

RESUMO. Um estudo comparativo dos esquemas de parametrização de cumulus de Kuo e Grell (CPSs), foi conduzido usando o Brazilian Regional Modeling System (BRAMS), para avaliar sua influência na simulação de tempestades severas. Neste contexto, analisou-se a ocorrência de uma frente fria, em 11 de dezembro de 2003, na região sul do Brasil. Os experimentos são idênticos, exceto pela diferença dos CPSs: o experimento SCKUO possui, como característica exclusiva, 0 uso do esquema de Kuo e 0 experimento SCGRELL, 0 uso do esquema de Grell. A validação das previsões da precipitação focou-se na comparação de dois aspectos: intensidade e cobertura de área. Também analisamos a simulação de parâmetros convectivos úteis no auxílio à identificação de ambientes atmosféricos favoráveis a convecção severa. Embora a simulação SCKUO represente melhor a cobertura de área da precipitação, subestimou a sua intensidade. Portanto, a melhor opção para esse caso é a parametrização de Grell, que melhor representou a intensidade da chuva. Ambos os experimentos simularam os parâmetros convectivos com boa aproximação, com ênfase no esquema de Grell, mostrando que o modelo de mesoescala é uma ferramenta útil na identificação de ambientes atmosféricos favoráveis para o desenvolvimento de tempestades convectivas severas, com grande contribuição dos CPSs

Palavras-chave: BRAMS, parametrização de convecção, tempestades severas.

\footnotetext{
${ }^{1}$ Instituto Nacional de Pesquisas Espaciais, Av. dos Astronautas, 1.758, Jd. Granja - 12227-010 São José dos Campos, SP, Brasil. Tel.: (12) $3186-8575$ -E-mail: mfapel@cptec.inpe.br

2 Sistema de Proteção da Amazônia (SIPAM), Centro Regional de Manaus, Divisão de Meteorologia, Av. do Turismo, 1.350, Tarumã - 69049-630 Manaus, AM, Brasil. Tel.: (92) 3652-6334; Fax: (92) 3652-6267 -E-mail: jaci.saraiva@sipam.gov.br
} 


\section{INTRODUÇÃo}

Os eventos severos representam uma ameaça potencial para atividades importantes como, por exemplo, aviação, agricultura, distribuição de energia elétrica e navegação. Portanto, identificar condições favoráveis à formação de sistemas convectivos severos é essencial para a antecipação de estratégias de eliminação e diminuiçãa do impacto adverso desses tipos de fenômenos atmostéricos.

Eventos como vendavais e tornados são mais raros em comparação com outros sistemas (como frentes frias) e em relação a sistemas de grande escala, vinculados ao padrão de circulação geral (como a Zona de Convergência do Atlântico Sul), porém não menos importantes.

Nechet (2002) realizou um estudo da ocorrência de tornados em território brasileiro. 0 autor listou a ocorrência desses fenômenos em vários estados e 0 atribui como um evento com grandes possibilidades de acontecer no Brasil, tendo classificação F0, próximo ao Equador e até o nível da escala F2 nas regiões Sudeste e Sul. Nechet ainda salienta que a prevenção é a forma mais adequada de se anteceder a uma determinada situação que seja adversa, e que, apesar de parecer caro (quando nada ocorre) uma prevenção pode trazer economia de somas vultuosas.

Portanto, a necessidade de prever eventos potencialmente destruidores torna-se mais evidente à medida que provocam irreparáveis perdas materiais e humanas na população, com profunda influência no seu retrocesso econômico e social.

Conforme Nascimento (2005), a infra-estrutura de modelagem numérica e rede observacional presente ou planejada para serviç̧os regionais de previsão do tempo possui potencial aplicação para a previsão de tempestades severas. 0 autor discute uma estratégia operacional de previsão de tempestades severas de possível aplicação no Brasil, e diz que é necessário estudar procedimentos que maximizem a extração de informação relevante dos dados observados e de modelos de mesoescala que identifiquem estes ambientes atmosféricos, visando uma implementação operacional.

Portanto, simulações numéricas são ferramentas de suma importância na investigação de fenômenos atmostéricos potencialmente destruidores. Dentro desse contexto, deve-se firmar 0 conceito de que eventos severos são extremamente susceptíveis a variação dinâmica e termodinâmica do ambiente em grande escala e na escala da nuvem.

Para grades com espaçamento horizontal maior do que $10 \mathrm{~km}$, a necessidade de se usar esquemas de parametrização convec- tiva, para simular com maior realidade os processos convectivos, é bem reconhecida. Sabe-se também que, em resoluções maiores (com espaçamento menor que $4 \mathrm{~km}$ ), certos tipos de convecção organizada podem ser simulados pela microfísica sem a necessidade de esquemas convectivos de escala subgrade. Nessa linha de pensamento, sabe-se que a parametrização de convecção desempenha um papel primordial na qualidade da simulação de eventos potencialmente destruidores, em grades com resolução inferior a $10 \mathrm{~km}$.

Bougeault (1985), afirma que uma parametrização convectiva de processos cumulus mais severos é de importância primária para a previsão numérica do tempo, tanto nos trópicos, quanto para previsões nas latitudes médias. Devido a esse fato, extensivos estudos foram desenvolvidos para avaliar e desenvolver novos esquemas, verificando e aperfeiçoando as teorias já existentes.

0 fluxo de calor latente na convecção cumulus e os transportes de calor e umidade nas nuvens podem modificar circulações atmosféricas em escalas maiores que a subgrade das nuvens. Por sua vez, a convergência de massa e vapor d'água em baixos níveis tem sido ligada observacionalmente com a ocorrência de convecção profunda de cumulus. Sasaki \& Lewis (1970), Lewis (1971) e Hudson (1971) acharam ligação entre a convecção ativa e áreas de convergência de massa e umidade sobre a região central dos Estados Unidos.

0 cisalhamento vertical do vento horizontal também tem um profundo efeito nos sistemas convectivos dos extratrópicos (Fritsch, 1975), mostrando que a eficiência da precipitação é uma função fortemente relacionada ao cisalhamento.

Estas relações satisfazem a necessária condição para a parametrização de convecção cumulus, onde a convecção deve ter forte ligação com parâmetros de larga escala. Estudos têm mostrado que os modelos prognósticos freqüentemente subestimam importantes eventos sinóticos quando a convecção cumulus exerce um papel principal (Kuo \& Anthes, 1984). Isto indica que importantes efeitos da convecção cumulus no ambiente não são propriamente parametrizados em modelos numéricos.

Portanto, diante do potencial cenário de destruição causado por eventos severos, torna-se importante estudar a influência das parametrizações de convecção na simulação desses fenômenos. Com esse objetivo, analisaram-se os resultados de simulações numéricas para um evento no qual áreas de instabilidade, associadas à passagem de uma frente fria, atuaram sobre 0 Rio Grande do Sul, no dia 11 de dezembro de 2003, provocando alagamentos na região metropolitana de Porto Alegre, Alegrete, Santana do Livramento e Lajeado. 


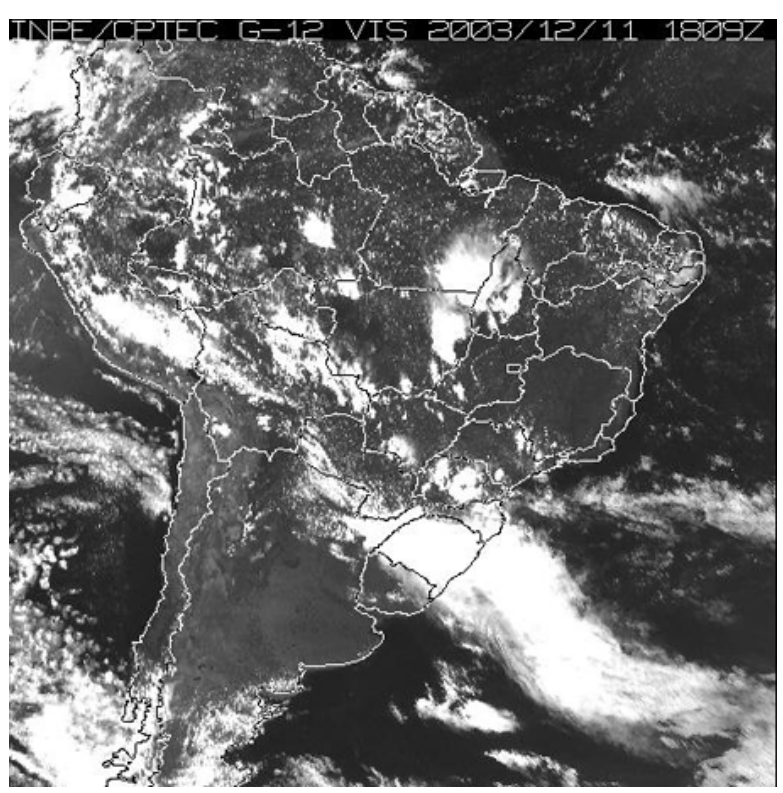

(a)

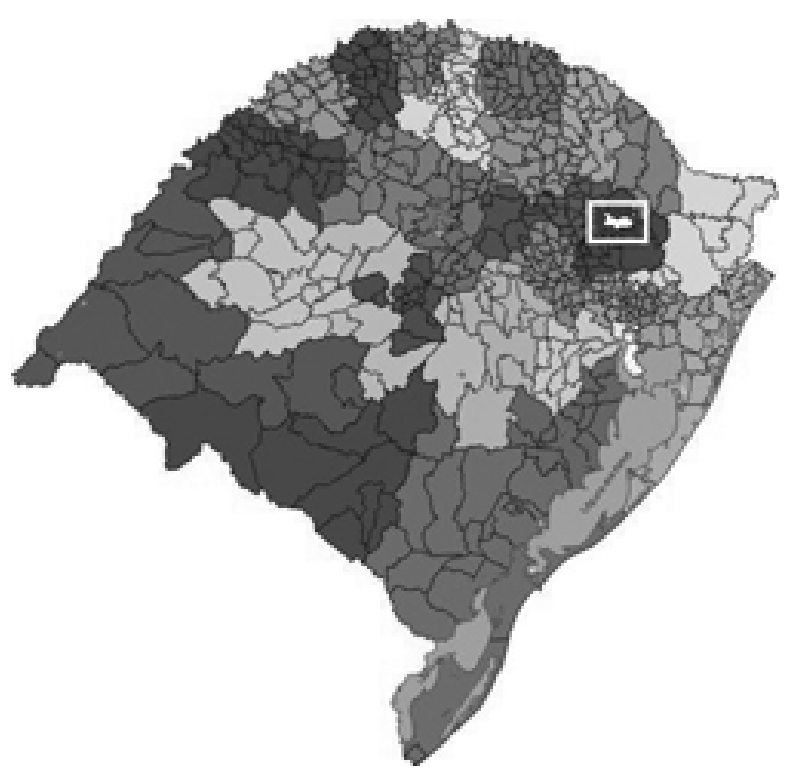

(b)

Figura 1 - (a) Imagem do satélite EUMETSAT no canal visível, às 18:00 TMG, do dia 11 de dezembro de 2003 e (b) Localização da cidade de Antônio Prado.

Porém, o fato que repercutiu em âmbito nacional, ocorreu na cidade de Antônio Prado, onde quatro crianças e um adulto morreram soterrados pelo teto de uma escola, que desabou durante o período da tarde. Conforme relato dos moradores, um tornado atingiu o local às 16h30min. Pelo menos 80 casas ficaram desteIhadas e 1,5 mil domicílios ficaram sem o fornecimento de energia elétrica. A Figura 1 mostra a localização da cidade de Antônio Prado e a imagem do satélite EUMETSAT no horário da ocorrência do provável tornado.

\section{METODOLOGIA}

\section{Experimentação numérica}

Os experimentos SCGRELL - que possui como característica peculiar a utilização da Parametrização Convectiva de Grell - e SCKUO - que possui como característica peculiar a utilização da Parametrização Convectiva de Kuo - foram iniciados utilizandose as análises do modelo Global T126L28 do CPTEC/INPE, com as fronteiras atualizadas a cada 6 horas. A resolução do modelo T126L28 é de aproximadamente $100 \mathrm{~km}$.

Alonso et al. (2004) testaram diferentes configurações do modelo BRAMS 2.0 para o mesmo evento ocorrido no dia 11 de dezembro de 2003. Foram confrontados, com os dados observados em estações meteorológicas de superfície, valores de precipitação simulados em 9 experimentos com distintas configurações. 0 experimento onde se obteve maior correlação com os dados observados para precipitação total acumulada foi o que utilizou as seguintes opções: parametrização convectiva de Grell (Grell \& Dévényi, 2002), tipo de fechamento denominado quase-equilíbrio (Grell, 1993), topografia de $20 \mathrm{~km}$, dados de temperatura da superfície do mar semanal com resolução de $50 \mathrm{~km}$, parametrização de microfísica aplicada a qualquer fase da água, incluindo o processo de precipitação, e parametrização de radiação segundo Mahrer \& Pielke (1977).

Portanto, para a definição das simulações realizadas neste capítulo, consideraram-se as características do experimento que obteve maior desempenho no trabalho de Alonso et al. (2004). As opções específicas são mostradas na Tabela 1. Embora a parametrização de Mahrer \& Pielke (1977) não considere o efeito radiativo das nuvens, esta não influenciou consideravelmente a simulação da precipitação nessa rodada. Um experimento semeIhante, porém usando a parametrização de radiação de Chen e Cotton, mostrou que não há diferenças significativas em relação ao experimento original.

No esquema de Mahrer \& Pielke (1977), os fluxos radiativos são calculados como função da temperatura vertical e da distribuiç̧ão de umidade. As características radiativas do líquido condensado e espécies de gelo não são parametrizadas. De acordo com Finley et al. (2001), essas características levam a uma superestimativa dos fluxos solares incidentes, em regiões onde há presença de nuvens. Porém, essas desvantagens não 
produzem muito impacto em áreas com cumulunimbus provenientes de sistemas dinâmicos, como zonas frontais.

Tabela 1 - Características dos experimentos.

\begin{tabular}{|c|c|c|}
\hline & SCKU0 & SCGRELL \\
\hline Grades & Grade 1-40 km & Grade 1-40 km \\
\hline Data Inicial & $11 / 12 / 03$ 00 UTC & $11 / 12 / 03$ 00 UTC \\
\hline $\begin{array}{c}\text { Campos } \\
\text { atmosféricos }\end{array}$ & $\begin{array}{c}\text { Global } \\
\text { CPTEC/INPE }\end{array}$ & $\begin{array}{c}\text { Global } \\
\text { CPTEC/INPE }\end{array}$ \\
\hline $\begin{array}{c}\text { Radiação de } \\
\text { onda curta }\end{array}$ & Mahrer/Pielke & Mahrer/Pielke \\
\hline $\begin{array}{c}\text { Radiação de } \\
\text { onda longa }\end{array}$ & Mahrer/Pielke & Mahrer/Pielke \\
\hline $\begin{array}{c}\text { Parametrização } \\
\text { de cumulus }\end{array}$ & Grade 1-Kuo & $\begin{array}{c}\text { Grade 1-Grell } \\
\text { Fechamento denominado } \\
\text { quase-equilíbrio }\end{array}$ \\
\hline
\end{tabular}

Tabela 2 - Características inalteradas em ambos experimentos.

\begin{tabular}{|l|l|}
\hline \multicolumn{1}{|c|}{ Característica } & \multicolumn{1}{c|}{ Valor } \\
\hline Resolução vertical no primeiro nível & 100 metros \\
\hline Razão de incremento & 1,2 \\
\hline$\Delta z$ máximo & 1.000 metros \\
\hline Passo de tempo & 60 segundos \\
\hline Pontos na fronteira lateral & 5 \\
\hline Escala de tempo na fronteira & 1.800 segundos \\
\hline Limite inferior no topo & 16.000 metros \\
\hline Escala de tempo no topo & 10.800 segundos \\
\hline Escala de tempo no centro & 0 segundo \\
\hline Esquema de topografia & Orografia média \\
\hline Atualização na radiação & 900 segundos \\
\hline Cumulus rasos & Desativada \\
\hline Atualização da convecção & 1.200 segundos \\
\hline & $\begin{array}{l}\text { (nível 3) - aplicada a } \\
\text { qualquer fase da água, } \\
\text { incluindo o processo } \\
\text { de precipitação }\end{array}$ \\
\hline Microfísica
\end{tabular}

Evidencia-se que as rodadas são idênticas, exceto pelo esquema de parametrização de cumulus. Na Figura 2 é mostrada a localização das respectivas grades.

Os experimentos numéricos foram rodados utilizando-se 0 modelo BRAMS 2.0 (Brazilian Regional Atmospheric Modeling System). Todas as simulações, independente do espaçamento de grade e das condições iniciais, incluíram: diferenciação na fronteira lateral de Klemp \& Wilhemson (1978) e parametrização do coeficiente $K$ de Mellor \& Yamada $(1974 ; 1982)$.
Os experimentos utilizaram arquivos de umidade do solo, gerados por um algoritmo desenvolvido por Gevaerd \& Freitas (2003) que utiliza um modelo de quatro camadas, gerando informações de umidade do solo através da precipitação estimada (mm/3h) pelo satélite TRMM ( Tropical Rainfall Measuring Mission).

Todas as simulações apresentaram características inalteradas, mostradas na Tabela 2. A Figura 2 mostra a grade utilizada nos dois experimentos.

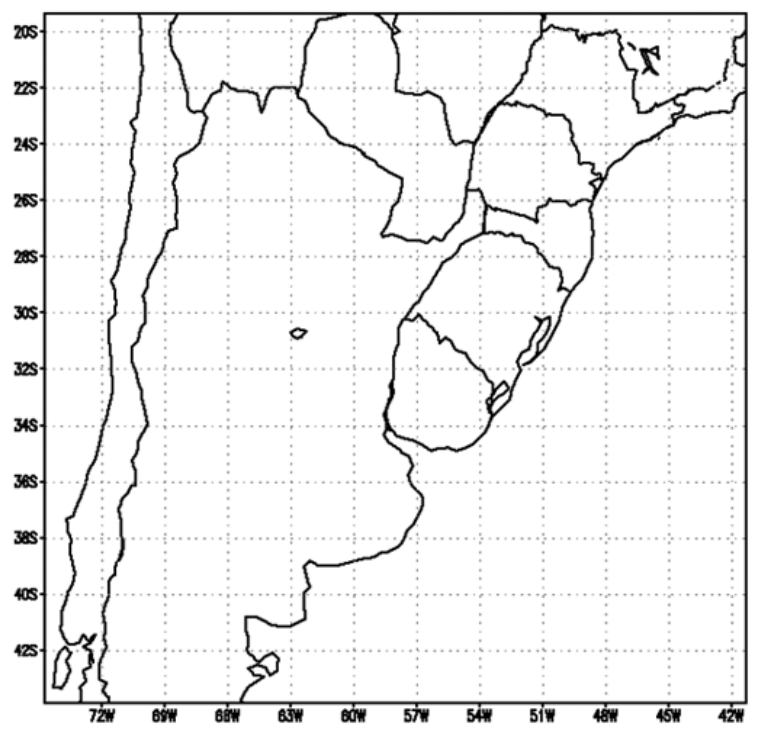

Figura 2 - Localização da grade nos experimentos SC.

\section{Esquemas convectivos}

Do amplo rol de parametrizações convectivas disponíveis, escoIheu-se 0 esquema de Grell e de Kuo para o presente estudo, cobrindo uma região distinta de complexidade e detalhamento físico. Conforme Cotton \& Anthes (1989), a principal consideração a ser feita sobre 0 esquema desenvolvido por Kuo é que há uma forte correlação entre a precipitação convectiva observada e 0 total de convergência de vapor d'água em larga escala numa coluna. Estas observações sugerem que a convergência de vapor d’água é uma variável muito útil para parametrizar os efeitos da convecção em modelos de larga escala, e muitas parametrizações cumulus tem sido baseadas na relação entre chuva convectiva e convergência de umidade na grande escala.

As modificações efetuadas por Tremback (1990), na versão original de Kuo (1974), incluem o efeito das correntes descendentes e o cálculo do parâmetro b (fração de convergência de umidade que é armazenada na coluna de convecção), com base na fórmula 
da eficiência de precipitação de Fritsch \& Chappell (1980):

$$
\begin{aligned}
\frac{\partial \theta}{\partial t_{\text {conv }}} & =L(1-b) \pi^{-1} I \frac{Q_{1}}{\int_{z s}^{z c t} Q_{1} d z}, \\
\frac{\partial r_{T}}{\partial t_{\text {conv }}} & =b I \frac{Q_{2}}{\int_{z s}^{z c t} Q_{2} d z},
\end{aligned}
$$

onde:

- $\theta$ é a temperatura potencial e $r_{T}$ é a razão de mistura em escala convectiva;

- zct é a altura do topo da nuvem, dada pelo nível acima do qual a temperatura potencial da adiabática úmida, que passa pelo nível de livre convecção, é menor do que a temperatura potencial do ponto de grade (ambiente);

- I é a quantidade de umidade fornecida pela grande escala à escala convectiva. $L$ é 0 calor latente de vaporização;

- $\pi$ é um número constante igual a 3,1416;

- $Q_{1}$ e $Q_{2}$ são os perfis verticais de aquecimento e umedecimento, respectivamente.

$Q_{1}$ é dado pela diferença entre a temperatura do ambiente e a de um perfil convectivo. Este perfil é uma média ponderada entre as correntes ascendentes e descendentes. A temperatura potencial da corrente ascendente é proveniente do nível que possui o maior valor de temperatura potencial equivalente nos três primeiros quilômetros acima do solo (nível fonte), levantando até o nível de livre convecção. Assume-se que a corrente descendente inicia-se no nível de mínima temperatura potencial equivalente da sondagem; quando esta chega a base da nuvem, encontrase $2 \mathrm{~K}$ mais fria que 0 ambiente e, na superfície, $5 \mathrm{~K}$ mais fria. 0 peso que pondera as duas correntes para o cálculo e de $Q_{1}$ é de $1 \%$ da corrente ascendente no nível de máxima temperatura potencial equivalente, 10\% no nível de livre convecção e 20\% no ponto de máximo fluxo de massa da corrente descendente (Menezes, 1998).

Para o cálculo de $Q_{2}$ definem-se duas regiões; logo abaixo da base da nuvem, o ambiente é secado com uma razão $I$ e entre a base da nuvem e a superfície, é secado até que fique com um valor de umidade específica constante na coluna. Na região da bigorna, há umedecimento na razão $b I$. Este umedecimento é constante e igual a 2/3 da altura entre o nível fonte e 0 topo da nuvem. A condensação na escala de grade ocorre se a razão de mistura de vapor supera a razão de mistura de saturação. Neste caso, o excesso de vapor é convertido em água líquida, mais especificamente em água de nuvem $\left(r_{c}\right)$.

A eficiência de precipitação é calculada através da formulação de Fritsch \& Chappell (1980). Assim, a eficiência é escrita em função do cisalhamento vertical do vento horizontal $(C I S)$, na camada de nuvem, da seguinte forma:

$$
\begin{aligned}
& C I S=\frac{\Delta V}{\Delta z} \quad \text { em } 10^{-3} s^{-1} \\
& \text { se }\left\{\begin{array}{c}
C I S<1,35 \Rightarrow(1-b)=0,9 \\
C I S>1,35 \Rightarrow(1-b)=1,591-0,639 C I S \\
+0,0953 C I S^{2}-0,00496 C I S^{3}
\end{array}\right\}
\end{aligned}
$$

Grell \& Dévényi (2002) desenvolveram uma nova parametrização convectiva com múltiplas hipóteses de fechamento. Pode-se escolher a opção "ensemble", que justamente é o conjunto dessas hipóteses, mediante técnicas de assimilação que determinam 0 valor ótimo para retroalimentação nos modelos tridimensionais.

No esquema de Grell há 108 modos diferentes de disparo da convecção, porém, os mais importantes são: a presença de convergência de umidade, instabilidade condicional e CAPE acima de $1500 \mathrm{~J} / \mathrm{kg}$. Conceitualmente, tal esquema é muito parecido com a parametrização convectiva de AS (Arakawa \& Schubert, 1974), modificações em relação ao esquema FC (Fritsch \& Chappell, 1980) foram inclusas recentemente (Grell \& Dévényi, 2002).

0 esquema original usa a função "cloud-work" usado por Arakawa \& Schubert. A variação local da energia cinética total é expressa por:

$$
\frac{d}{d t} \overline{K E}_{t o t}=A_{t o t}(\lambda) m_{0}(\lambda)-D_{t o t}(\lambda),
$$

onde $m_{o}(\lambda)$ é o fluxo de massa no nível de origem, $D_{\text {tot }}(\lambda)$ é a dissipação total de energia cinética e $A_{\text {tot }}(\lambda)$ é a função de trabalho da nuvem total, definida como a medida da eficiência da geração de energia cinética nas correntes ascendentes e descendentes. Um valor positivo de $A_{\text {tot }}(\lambda)$ é necessário para a geração de energia cinética das nuvens do tipo $\lambda$, portanto, $A_{\text {tot }}(\lambda)>0$ pode ser considerado com um critério generalizado para a instabilidade convectiva.

A atividade convectiva é relacionada com a variação no tempo do parâmetro $A$, que é escrito pela soma de dois termos, um devido aos processos de larga escala $F(\lambda)$ e outro devido às nuvens.

$$
\frac{d A_{t o t}(\lambda)}{d t}=\left[\frac{d A_{t o t}(\lambda)}{d t}\right]_{c}+F(\lambda)
$$


sendo:

$$
\left[\frac{d A_{t o t}(\lambda)}{d t}\right]_{c}=\int_{\lambda} K\left(\lambda, \lambda^{\prime}\right) m_{b}(\lambda) d \lambda,
$$

onde $m_{b}(\lambda)$ é o fluxo de massa na base da corrente ascendente e $K\left(\lambda, \lambda^{\prime}\right)$ é o Kernel. 0 Kernel é uma expressão para a interação entre nuvens (correntes ascendentes e descendentes) e depende de algumas propriedades das nuvens, incluindo o fluxo de massa em cada nível e a taxa de desentranhamento. Esse valor é tipicamente negativo, e é um meio de as nuvens atuarem para estabilizar 0 ambiente, principalmente através do aquecimento adiabático na subsidência compensatória.

Supondo que a nuvem ocupa uma fração da grade (aproximadamente 1\%) em modelos com espaçamento maior que $10 \mathrm{~km}$, esta, não pode ser resolvida explicitamente. Arakawa \& Schubert (1974) discutem que no conceito de instabilidade condicional de segunda ordem (CISK), a escala cumulus e os movimentos na escala de um ciclone cooperam mutuamente, as nuvens cumulus provêm o aquecimento que dirige o ciclone, e o ciclone provém a umidade que mantém as nuvens cumulus. Há, portanto, a nítida necessidade de esquematizar essa interação entre a subgrade e a larga escala.

0 esquema de Grell assume que as nuvens convectivas profundas possuem o mesmo tamanho, calculado conforme a taxa de entranhamento na base da nuvem, pela seguinte formulação:

$$
\mu_{u e}(z, \lambda)-\mu_{n d}(z, \lambda)=\frac{1}{m_{u}(z, \lambda)} \frac{\partial m_{u}(z, \lambda)}{\partial z}
$$

onde $\mu_{u e}$ é a taxa de entranhamento fracional, $\mu_{u d}$ é a taxa de desentranhamento fracional ( $u$ denota corrente ascendente), e $m$ é 0 fluxo de massa, onde cada subconjunto é normalizado pelo fluxo de massa na base da nuvem.

\section{Dados utilizados}

Para a obtenção dos perfis de temperatura potencial equivalente de saturação, dos gráficos Skew-T Log-P e dos índices termodinâmicos observados, usaram-se dados obtidos por radiossondagem, da estação SBPA, no horário das 00:00 e 12:00 TMG, disponibilizados publicamente na homepage da Universidade de Wyoming - WY/EUA (http://www.weather.uwyo.edu).

Para validar os dados de precipitação acumulada, simulados neste trabalho, utilizaram-se dados de precipitação diária, coletados nas 21 estações do INMET distribuídas pelos estados do Rio Grande do Sul e Santa Catarina; e dados estimados por satélite, conforme o projeto Global Precipitation Climatology Project (GPCP - http://precip.gsfc.nasa.gov).
0 GPCP é um elemento da Global Energy and Water Cycle Experiment (GEWEX) do World Climate Research Program (WCRP). No presente estudo, utilizou-se o produto GPCP1DD, que fornece os dados de precipitação diária em pixels de $1^{\circ} \times 1^{\circ}$. Este produto primariamente é uma combinação dos dados de satélite SSM/I, IR (sensor do satélite DMSP - Defense Meteorological Satellite Program) e TIROS-N Operacional Vertical Sounder (TOVS).

\section{Método de validação do modelo}

A correspondência ponto a ponto entre a previsão do modelo e 0 dado observado, de uma mesma variável, permite um teste quantitativo da capacidade do modelo. Para esse tipo de validação, utilizou-se o erro médio quadrático normalizado pelo viés Médio (EmqMV), obtido subtraindo o viés médio, conforme as seguintes equações:

$$
\begin{aligned}
\operatorname{Vies} M(H i) & =\frac{\sum_{n=1}^{N} P_{i}-P_{i o b s}}{N}, \\
\operatorname{EmqMv}(H i) & =\frac{\sum_{n=1}^{N} \sqrt{\left(P_{i}+P_{\text {iobs }}-\operatorname{Vies} M\right)^{2}}}{N}
\end{aligned}
$$

onde $N$ é o número de estações e $H_{i}$ é 0 tempo de simulação.

Um problema da validação ponto a ponto, no entanto, é a diferença espacial e temporal na disposição dos dados observados. Através destes índices, pode-se quantificar o desempenho do modelo quanto à magnitude do parâmetro analisado, porém, nada se pode afirmar quanto à fase. Pielke \& Mahrer (1978) aplicaram uma técnica eficaz para analisar o erro de posicionamento entre as áreas observadas e prognosticadas. Esta metodologia originalmente foi aplicada para estudar a fração predita da convergência de níveis baixos (estimada por velocidade vertical) que é coberta por chuva e a fração de chuva que ocorre fora das respectivas zonas de convergência.

Para ilustrar o procedimento, considera-se uma área cujo domínio é $D_{x} D_{y}, S$ é a área do domínio coberta pela variável prognosticada, num dado intervalo de magnitude, e $R$ é a área coberta pela variável observada, neste mesmo intervalo de magnitude (Fig. 3). Aplicam-se as seguintes definições:

(a) $F_{e}=\frac{(S \cap R)}{R}$ é a fração de área observada coberta pela área simulada, de uma variável num dado intervalo de magnitude.

(b) $F_{m}=\frac{S}{D_{x} D_{y}}$ é a fração do domínio do modelo coberta 
pelas áreas simuladas, de uma variável num dado intervalo de magnitude.

(c) $F_{C}=\frac{(S \cap R)}{S}$ é a fração de área simulada coberta pela área observada, de uma variável num dado intervalo de magnitude.

Considera-se uma boa capacidade do modelo quando a razão entre $F_{E}$ e $F_{m}$ é maior que 1 . Uma simulação é considerada praticamente perfeita quando $F_{C}$ é igual a 1 .

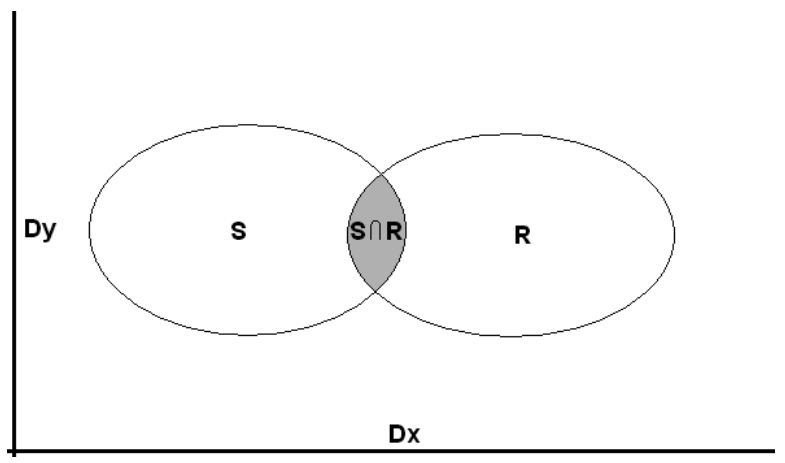

Figura 3 - Ilustração esquemática da justaposição dos campos simulados ( $S$ ) e observados $(R)$. Os dois campos são coincidentes em $S \cap R$.

\section{Parâmetros convectivos analisados}

Foram analisados diversos parâmetros convectivos conforme a estratégia observacional discutida por Nascimento (2005). Entre os parâmetros analisados, destacam-se: 0 índice de instabilidade $K, 0$ índice de instabilidade total totals $(T T)$, 0 índice de instabilidade por levantamento ( $L E V$ ou lift), a energia potencial convectiva disponível $(C A P E)$ e a inibição convectiva (CINE).

0 índice de instabilidade $K$ possui a tendência de capturar condições favoráveis à ocorrência de tempestades em ambientes úmidos em toda a troposfera, como é típico de ambientes tropicais, e apresentar valores relativamente baixos quando há intrusão de ar seco em níveis baixos e médios, aumentando a depressão do bulbo úmido em $700 \mathrm{hPa}$ (Nascimento, 2005).

Portanto, há possibilidade de um ambiente apresentar um índice $K$ baixo, uma $C A P E$ alta e $I L E V$ negativo, e caracterizar a ocorrência de tempestades severas, com menor taxa de precipitação, mas com ventos intensos.

Por sua vez, o cálculo da $C A P E$ é sensível à altura dos níveis de $N C E$ e $N E L$ e à escolha da própria parcela de ar ascendente. Portanto, para uma melhor caracterização da instabilidade convectiva da atmosfera, é plausível analisar os índices termodinâmicos em conjunto, como $C A P E, K, T T$,
I L E V e o próprio gradiente vertical da temperatura do ambiente (lapse rate).

Porém, a forçante dinâmica é de extrema importância na formação e manutenção de células convectivas, por isso, alguns parâmetros que mesclam informações sobre a dinâmica e termodinâmica do ambiente foram analisados.

Um parâmetro de cisalhamento útil em previsão convectiva severa é o denominador do número de Richardson volumétrico ( $D N R V$ ), e é dado por:

$$
D N R V=0,5\left(\bar{u}^{2}+\bar{v}^{2}\right)\left[m^{2} s^{-2}\right]
$$

onde $\bar{u}$ e $\bar{v}$ são, respectivamente, as componentes zonal e meridional do vetor diferença entre o vento médio no nível de $500 \mathrm{hPa}$ e vento médio no nível de $1000 \mathrm{hPa}$, ponderados pela densidade.

Nascimento (2005) sugere que valores entre 40 e $100 \mathrm{~m}^{2} \mathrm{~s}^{-2}$ são indicativos de ambientes condizentes ao desenvolvimento de tempestades severas, mas devem ser analisados junto com a $C A P E$ e a Helicidade para apontar situações tornádicas, por exemplo.

Outro conceito útil na caracterização de ambientes favoráveis a ocorrência de tempestades severas é a Helicidade. Em sua forma geral, este parâmetro é expresso como segue:

$$
H=0,5(\vec{V} \cdot(\nabla \times \vec{V}))\left[m s^{-2}\right]
$$

onde $\vec{V}$ é o vetor vento tridimensional $(\nabla \times \vec{V}$ é, portanto, 0 campo de vorticidade tridimensional $\vec{\omega}$ ).

A helicidade é uma variável cuja magnitude depende do referencial utilizado para seu cálculo. Um referencial conveniente para o cálculo de $H$ em meteorologia é aquele que se desloca junto com as tempestades, caracterizando a helicidade relativa $(H R)$. A $H R$ empregada em meteorologia é definida como (Davies-Jones et al., 1990).

$$
H R=-\int_{z s}^{h} \hat{K} \cdot\left[(\vec{V}-\vec{c}) \times \frac{\partial \vec{V}}{\partial z}\right] d z\left[m^{2} s^{-2}\right]
$$

onde $\vec{c}$ é o vetor deslocamento do sistema convectivo, calculado empiricamente pelo método de Davies \& Johns (1993) e adaptado para o hemisfério sul por Nascimento (2005). $\hat{k}$ é o vetor unitário na direção vertical, zs é o nível de superfície e $h$ é o nível do topo da camada de influxo, sendo considerada $3 \mathrm{~km}$ nesse estudo.

Tempestades severas tendem a ocorrer em ambientes com $H R$ acima de $150 \mathrm{~m}^{2} \mathrm{~s}^{-2}$ (ou abaixo de $-150 \mathrm{~m}^{2} \mathrm{~s}^{-2}$ para 0 hemisfério sul). Esses valores são baseados em estudos para os Estados Unidos, porém, podem ser aplicados para o Brasil. 

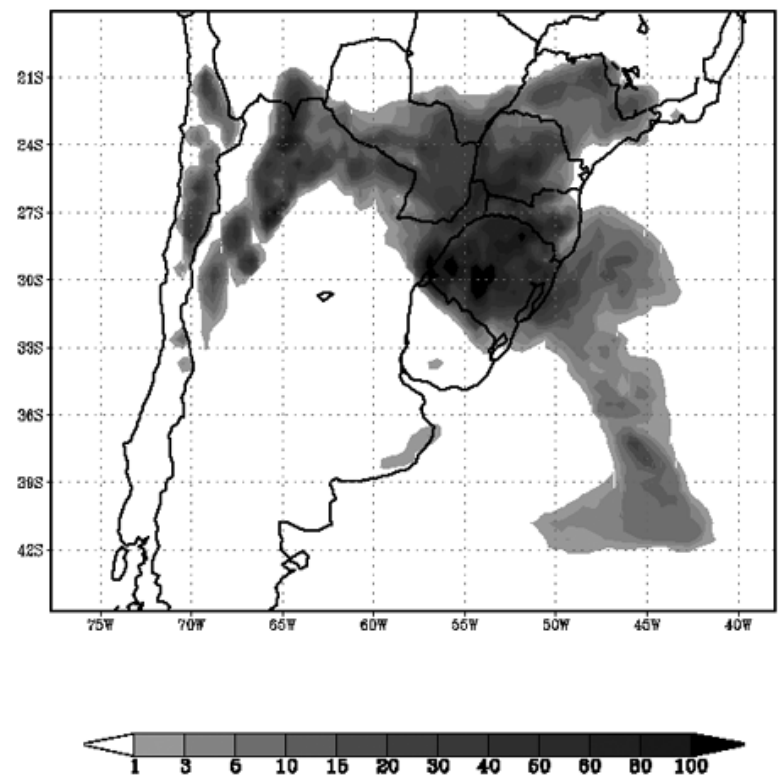

(a)
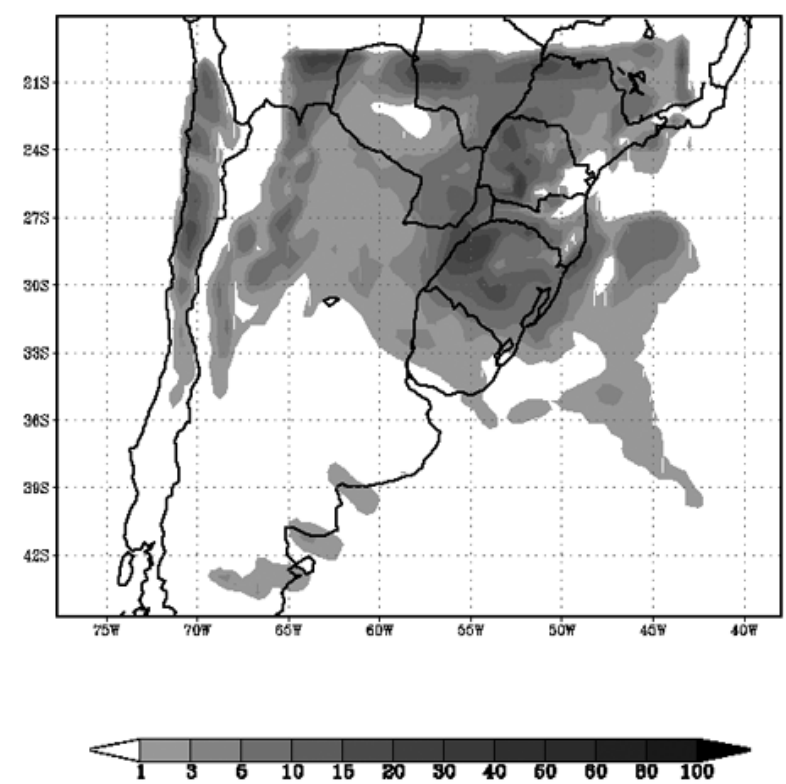

(b)

Figura 4 - Precipitação convectiva acumulada no dia 11 de dezembro de 2003, em mm/dia, no experimento (a) SCGRELL e (b) SCKU0 para a grade 1. (Continuação da figura na próxima página).

Nascimento (2005), baseado em resultados numéricos, salienta que na presença de altos valores de $C A P E$ e helicidade relativa e valores moderados de $D N R V$, há indicação de desenvolvimento de tempestades severas com rotação em baixos níveis, apontando potenciais situações tornádicas.

\section{ANÁLISE COMPARATIVA DA PRECIPITAÇÃO}

A Figura 4 mostra 0 comportamento da precipitação acumulada no dia 11 de dezembro de 2003, estimada por satélite, no projeto GPCP e simulada pelos experimentos. Realizou-se um corte na grade global com intuito de evidenciar a disposição da precipitação estimada sobre o estado do Rio grande do Sul. Observam-se núcleos máximos de precipitação com valores entre 80 e $90 \mathrm{~mm}$ na extensão da Lagoa dos Patos e noroeste do estado.

A parametrização convectiva de Grell (Grell \& Dévényi, 2002) gera núcleos mais intensos de precipitação diária acumulada (acima de $80 \mathrm{~mm}$ ) em todo 0 estado gaúcho, no extremo norte da Argentina e no Paraguai. Já o experimento SCKUO, cuja característica peculiar é 0 uso da parametrização convectiva de Kuo (Tremback, 1990), simula precipitação numa média de $15 \mathrm{~mm} / \mathrm{dia}$, sem núcleos mais significativos. No experimento SCGRELL evidencia-se a disposição da banda de precipitação acumulada na direção predominante de noroeste-sudeste, con- gruente ao observado por satélite.

Para uma comparação mais detalhada da precipitação, dividiram-se os estados de Santa Catarina e Rio Grande do Sul em cinco regiões, classificadas quanto à topografia e características geomorfológicas (Fig. 5). Observando a Tabela 3, nota-se a superioridade do experimento que utiliza a parametrização convectiva de Grell, com o fechamento de quase-equilíbrio (Grell, 1993) na simulação da magnitude da precipitação total acumulada em praticamente todas regiões analisadas, com exceção na área que compreende a denominada Depressão Central.

Tabela 3 - ViésM (viés médio) e EmgMV (Erro médio quadrático normalizado pelo Viés), em milímetros acumulados no período das 12:00 TMG do dia 11/12/03 às 12:00 TMG do dia 12/12/03. Os menores erros estão destacados em negrito.

\begin{tabular}{|l|c|c|c|c|}
\hline \multirow{2}{*}{} & \multicolumn{2}{|c|}{ SCGRELL } & \multicolumn{2}{c|}{ SCKUO } \\
\cline { 2 - 5 } & ViésM & EmgMV & ViésM & EmqMV \\
\hline Santa Catarina & $\mathbf{- 1 1 , 4 7}$ & $\mathbf{9 , 1 8}$ & $-21,45$ & 17,16 \\
\hline Planalto Meridional & $\mathbf{- 1 , 0 2}$ & $\mathbf{0 , 9 1}$ & $-33,75$ & 30 \\
\hline Depressão Central & 18,41 & 9,20 & $\mathbf{- 1 6 , 2 8}$ & $\mathbf{8 , 1 4}$ \\
\hline Escudo Sul-Riograndense & $\mathbf{1 , 4 4}$ & $\mathbf{0 , 7 2}$ & $-26,45$ & 13,22 \\
\hline Planície Costeira & $\mathbf{1 , 1 7}$ & $\mathbf{0 , 7 8}$ & 11,55 & 7,7 \\
\hline
\end{tabular}

0 experimento SCGRELL superestimou a precipitação observada na maioria das regiões, porém subestimou consideravelmente 0 dado medido no estado de Santa Catarina. Já o expe- 


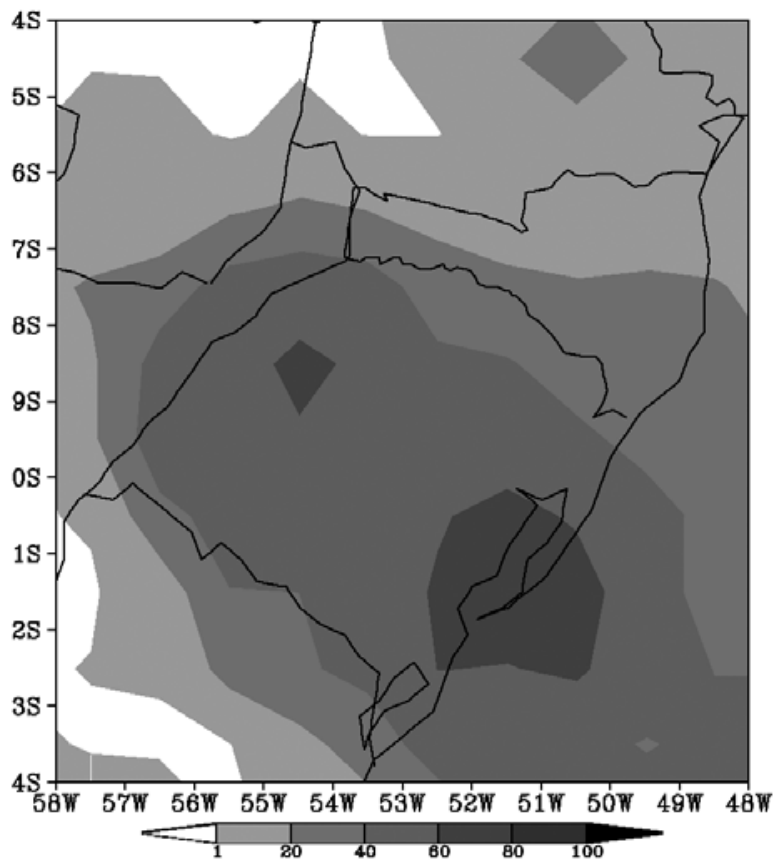

(C)

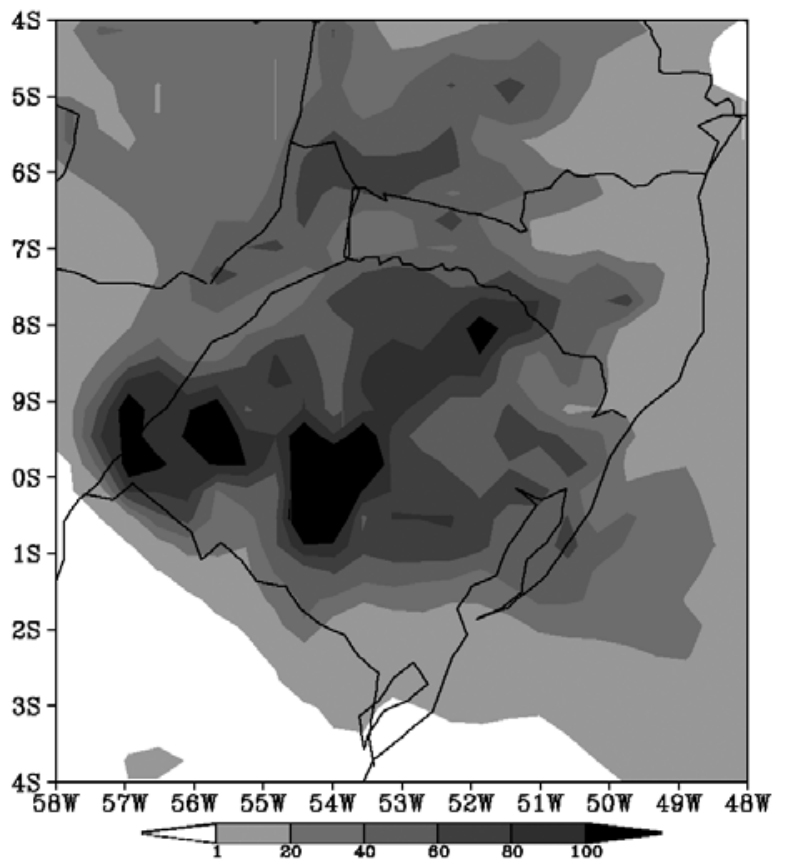

(d)

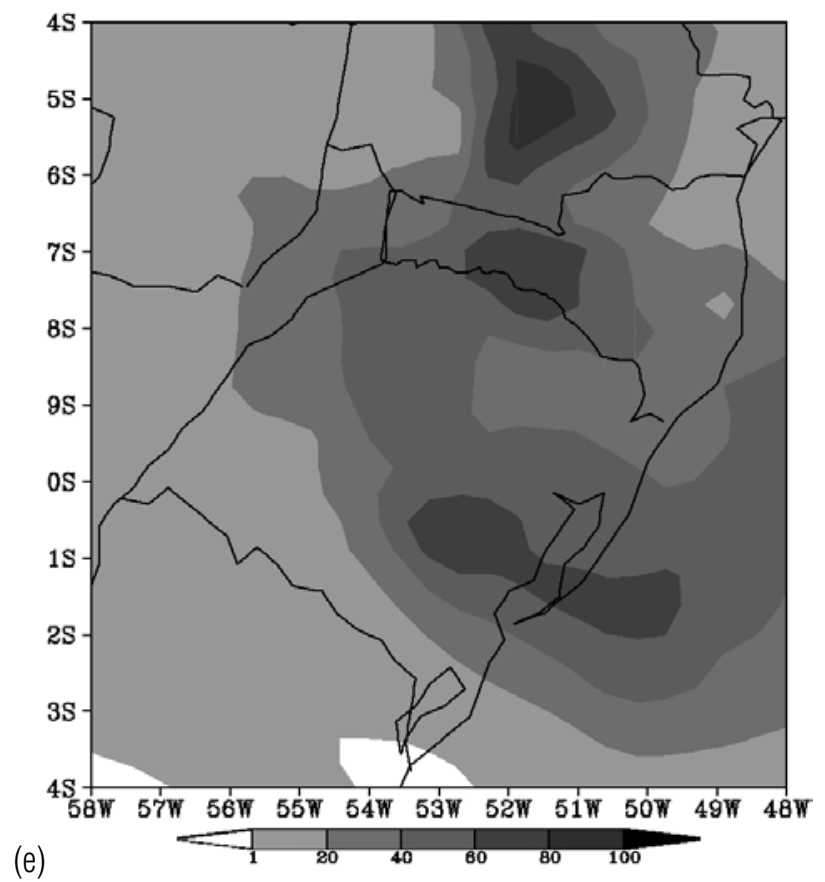

Figura 4 (continuação da figura da página anterior) - Os quadros (c), (d) e (e) referem-se a um corte realizado na grade para mostrar a disposição da precipitação acumulada sobre o estado do Rio Grande do Sul, observada pelo satélite GPCP e simulada pelos experimentos SCGRELL e SCKUO, respectivamente. 


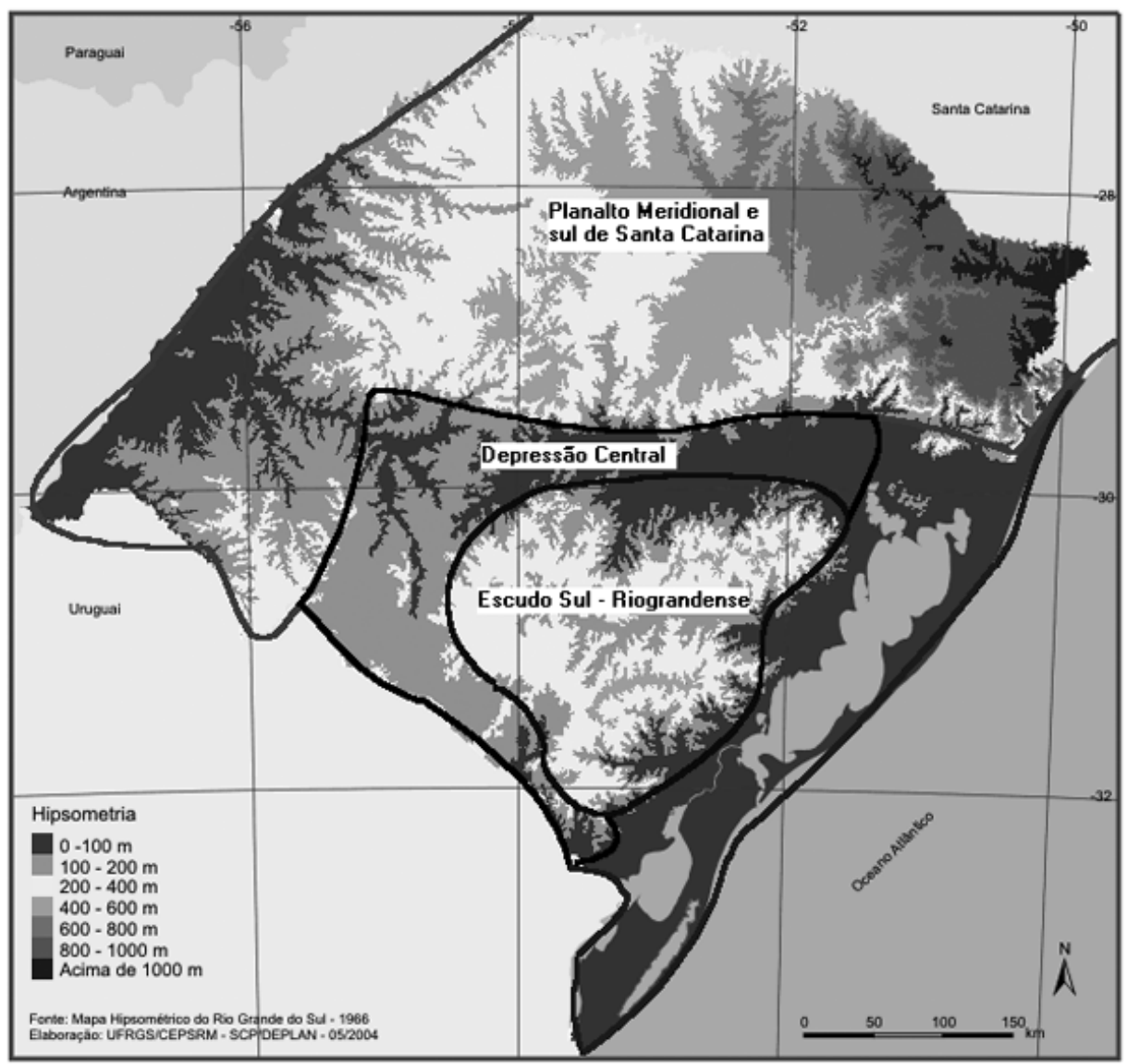

Figura 5 - Mapa hipsométrico com as áreas de estudo destacadas conforme características topográficas e geomorfológicas.

rimento SCKUO subestimou significativamente a precipitação em boa parte do domínio estudado, porém superestimou o dado medido nas estações localizadas ao longo da Planície Costeira.

Tabela 4 - Índices de posicionamento dos dados simulados de precipitação acumulada no dia 17 de janeiro de 2005 em relação ao observado nas 21 estações do INMET para (a) $\mathrm{P} \leq 20 \mathrm{~mm} / 24 \mathrm{~h}$; (b) $20 \leq \mathrm{P} \leq 50 \mathrm{~mm} / 24 \mathrm{~h}$ e (c) $\mathrm{P} \geq 50 \mathrm{~mm} / 24 \mathrm{~h}$.

\begin{tabular}{|c|c|c|c|c|c|c|}
\hline & \multicolumn{3}{|c|}{$F_{C}$} & \multicolumn{3}{c|}{$F_{E} / F_{m}$} \\
\cline { 2 - 7 } & $\mathrm{a}$ & $\mathrm{b}$ & $\mathrm{c}$ & $\mathrm{a}$ & $\mathrm{b}$ & $\mathrm{c}$ \\
\hline SCGRELL & 1 & 0,443 & 0,685 & 3,346 & 0,697 & 2,208 \\
\hline SCKU0 & 0,403 & 0,724 & 0 & 1,348 & 1,14 & 0 \\
\hline
\end{tabular}

As informações de precipitação acumulada em 21 estações espalhadas no Rio Grande do Sul e Santa Catarina foram interpoladas numa grade espaçada em intervalos de $1,36^{\circ}$, utilizando-se 0 método do inverso quadrado da distância. 0 posicionamento das regiões interpoladas foi comparado com os dados simulados, que obtiveram igual tratamento. Conforme visto na Tabela 4, o experimento SCGRELL apresentou boa capacidade de simular 0 posicionamento dos núcleos de precipitação $\left(F_{E} / F_{m}>1\right)$ nos intervalos menores que 20 mm/24 h e maiores que $50 \mathrm{~mm} /$ 24 h, em relação ao observado nas estações. Por conseguinte, o experimento SCKUO apresentou boa capacidade de simular 0 posicionamento dos núcleos de precipitação nos intervalos inferiores a $50 \mathrm{~mm} / 24 \mathrm{~h}$. Para a magnitude que compreende $20 \mathrm{e}$ $50 \mathrm{~mm} / 24 \mathrm{~h}$, evidencia-se a superioridade do experimento que utiliza a parametrização convectiva de Kuo.

\section{ANÁLISE DO AMBIENTE SIMULADO}

\section{Características termodinâmicas do ambiente simulado}

A Figura 6a mostra o ambiente observado na estação aerológica SBPA no dia 11 de dezembro de 2003 às 00:00 TMG. Os perfis de temperatura e temperatura do ponto de orvalho caracterizam claramente um ambiente com ausência de nuvens. A presença de uma camada de inversão em baixos níveis foi devidamente simulada pelos experimentos SCGRELL e SCKUO. A área nega- 
tiva presente em todo perfil vertical, em relação à ascensão forçada da parcela desde a superfície, caracteriza um ambiente préconvectivo essencial para o disparo da convecção.

Ambos os experimentos apresentaram índices $K$ e $T T$ menores que 0 dado observado (em média uma diferença de $8^{\circ} \mathrm{C}$ ), e um $I L E V$ acima do que foi observado. Registrou-se ausência de $C A P E$ e $C I N E$ no ambiente simulado e observado.

Conforme mostrado na Figura 7; a atmosfera simulada para 0 horário das 12:00 TMG em Porto Alegre (SCGRELL) apresenta boa correlação com 0 dado medido. 0 experimento SCGRELL possui índices $K$ e $T T$ menores que 0 dado observado (uma diferença de $4^{\circ} \mathrm{C}$ e $7^{\circ} \mathrm{C}$, respectivamente). 0 índice de instabilidade por levantamento teve um comportamento bem distinto em cada simulação: mais instável que o valor observado, no experimento SCGRELL; e mais estável em relação ao observado, no experimento SCKUO. 0 ambiente simulado pelo experimento SCKUO apresenta ausência de $C A P E$ e valores de $K$ e $T T$ bem menores que 0 ambiente observado.

É importante salientar que 0 ambiente observado às 12:00 TMG já não é pré-convectivo; claramente percebe-se a geração de nuvens no ambiente. 0 fato de a sondagem estar saturada até aproximadamente $800 \mathrm{hPa}$ (SCGRELL) e $500 \mathrm{hPa}$ (SCKUO) evidencia a simulação de precipitação sobre Porto Alegre, já nesse horário.

Observa-se na Figura 8, a condição estável do ambiente, presente em praticamente toda troposfera, e uma camada quase neutra entre os níveis de 850 e $500 \mathrm{hPa}$. Acima de $400 \mathrm{hPa}$, os perfis verticais simulados de temperatura potencial equivalente de saturação acompanham com ótima aproximação o perfil observado. Nas camadas inferiores, as simulações subestimaram 0 valor observado. Com posse nas informações do perfil vertical de temperatura potencial equivalente de saturação $\left(\theta_{e s}\right)$, pode-se afirmar que a região de Porto Alegre, no horário das 12:00 TMG, está com ausência de instabilidade condicional.

Analisando-se os gráficos Skew-T Log-P simulados para a cidade de Antônio Prado, em ambos experimentos (Fig. 9), podemos extrair uma série de informações sobre 0 estado do ambiente às 18:00 TMG. Primeiramente, é importante salientar que os perfis de temperatura e temperatura do ponto de orvalho estão muito próximos em toda troposfera, no experimento SCKUO, e acompanham as curvas pseudo-adiabáticas. Esse comportamento demonstra que movimentos ascendentes na nuvem provavelmente foram disparados pelo fluxo de calor latente do sistema.

0 índice Lift (ILEV) é igual a $-5^{\circ} \mathrm{C}$, no experimento SCGRELL, e $-2^{\circ} \mathrm{C}$, quando simulado em SCKUO. Os índices $K$ e $T T$ também são superiores no experimento SCGRELL, e de- nota atmosfera com alto potencial a ocorrência de tempestades. Logo, do ponto de vista da flutuabilidade, tempestades se desenvolvendo nos ambientes simulados pelo experimento SCGRELL teriam maior potencial para se tornarem severas do que nos ambientes simulados pelo experimento SCKUO, do ponto de vista operacional.

\section{Características dinâmicas do ambiente simulado}

Um aspecto importantíssimo na formação de supercélulas é 0 cisalhamento vertical do vento horizontal em baixos e médios níveis. Não obstante, sua combinação com outros fatores como $C A P E$ e Helicidade fornecem uma boa informação qualitativa, indicando a possibilidade de tempestades severas. Se observarmos 0 índice $D N R V$, no horário das 18:00 TMG, podemos ressaltar valores moderados de cisalhamento na região nortenordeste do Rio Grande do Sul simulado pelo experimento SCGRELL (acima de $50 \mathrm{~m}^{2} \mathrm{~s}^{-2}$ ). Há um pequeno núcleo de convergência de umidade com valor de $-5 \times 10^{-5} \mathrm{~g} \cdot \mathrm{kg}^{-1} . \mathrm{s}^{-1}$ sobre a fronteira nordeste do Rio Grande do Sul (Fig. 10).

Analisando-se a Helicidade Relativa simulada no experimento SCGRELL, nos primeiros $3 \mathrm{~km}$ (Fig. 11), mediante uma interpolação dessa variável em 32 pontos nos estados do Rio Grande do Sul e Santa Catarina, espaçados em 1 grau, notamos um núcleo máximo acima de $-360 \mathrm{~m}^{2} \mathrm{~s}^{-2}$ sobre a região nordeste do estado. Esses valores indicam um escoamento com forte tendência helicoidal. Portanto, valores altos de $C A P E$, valores significativos de Helicidade Relativa e valores moderados de $D N R V$ (entre 40 e $100 \mathrm{~m}^{2} \mathrm{~s}^{-2}$ ) indicam forte tendência à ocorrência de tempestades severas com probabilidade a formação de tornados, dando uma base qualitativa para 0 tornado que foi documentado pelos moradores de Antônio Prado no dia 11 de dezembro de 2003 às 16h00min horário local (18:00 TMG).

Observando-se o comportamento do índice $D N R V$ (Fig. 12) para 0 experimento SCKUO evidenciam-se valores em torno de $45 \mathrm{~m}^{2} \mathrm{~s}^{-2}$ em praticamente todo estado. 0 fato da simulação SCKUO não apresentar núcleos de convergência de umidade sobre 0 estado do Rio Grande do Sul e arredores, possivelmente explica porque a parametrização de Kuo subestimou o valor observado de precipitação total diária.

Observando a Figura 13a, nota-se um escoamento de noroeste em $925 \mathrm{hPa}$, com ventos acima de $16 \mathrm{~m} / \mathrm{s}$, que se estendem pelo Paraguai até o Rio Grande do Sul, apresentando um máximo de aproximadamente $24 \mathrm{~m} / \mathrm{s}$, sobre a região nordeste do estado. Tal configuração, aliada a concentração significativa de umidade específica sobre a extensão deste escoamento (Fig. 13b), eviden- 

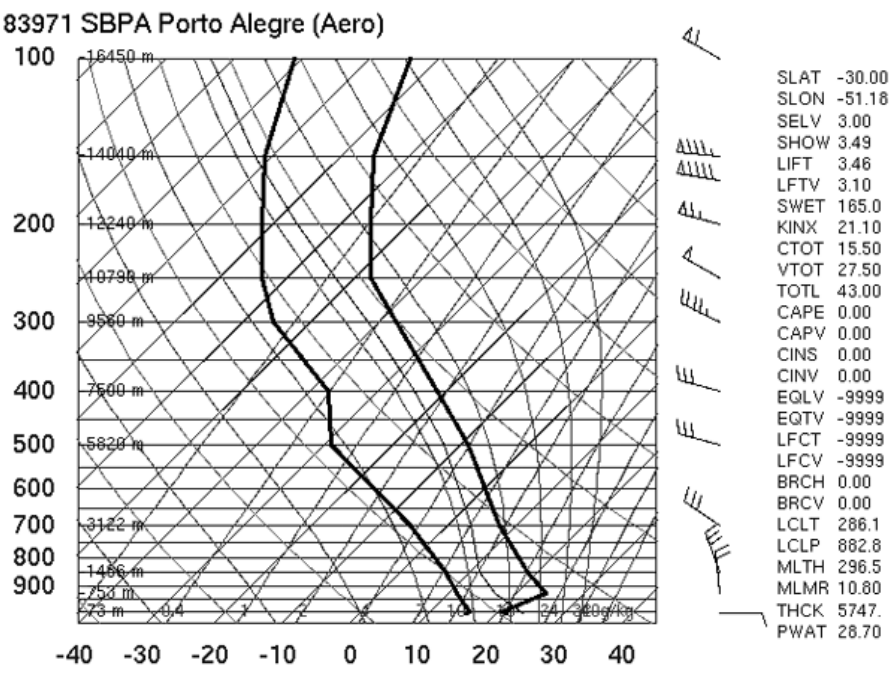

(a)

00211 Dec 2003

University of Wyoming

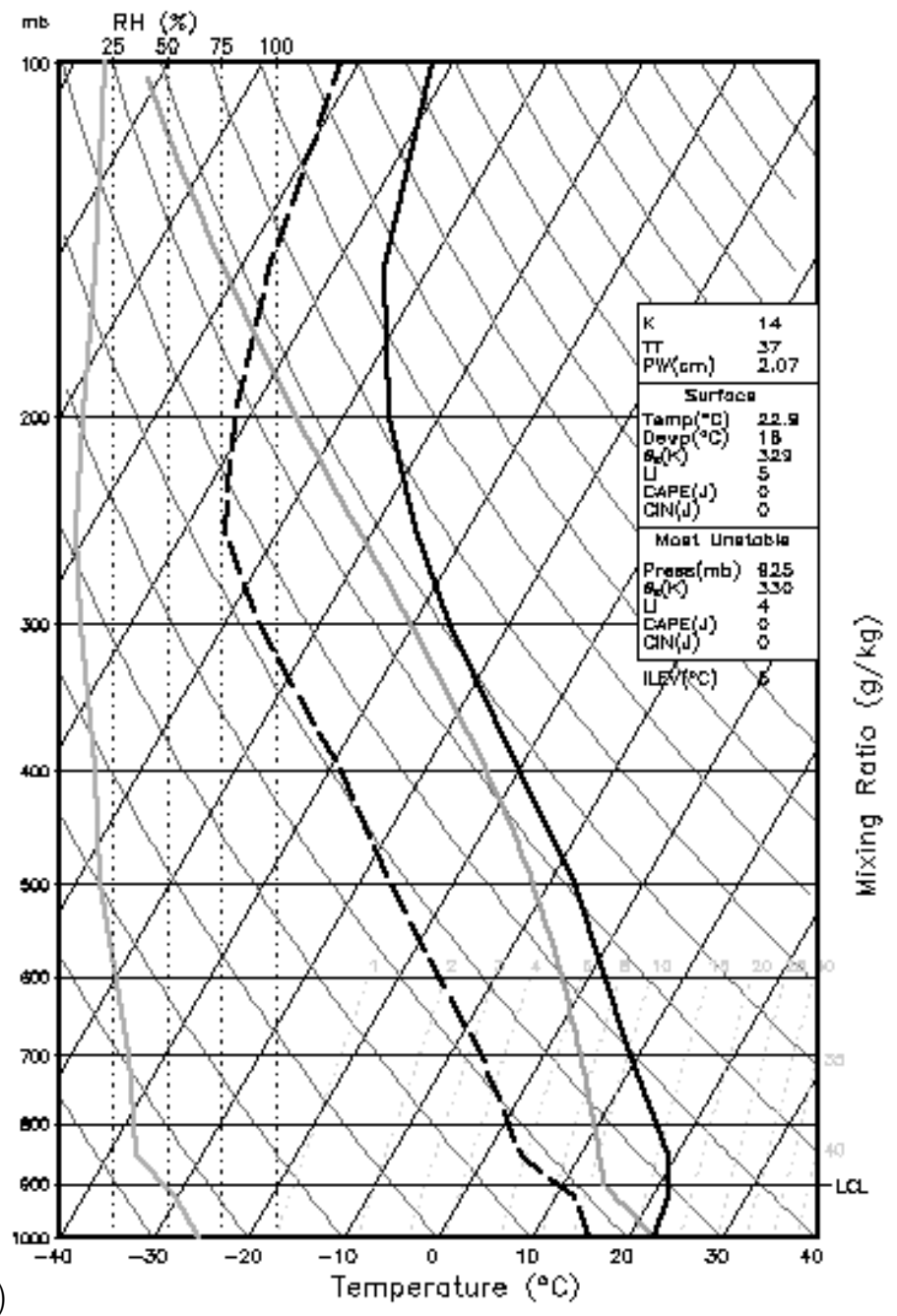

Figura 6 - Porto Alegre: 00:00 TMG do dia 11/12/2003: (a) Gráfico Skew-T Log-P observado; (b) Gráfico Skew-T Log-P simulado pelo experimento SCGRELL. 


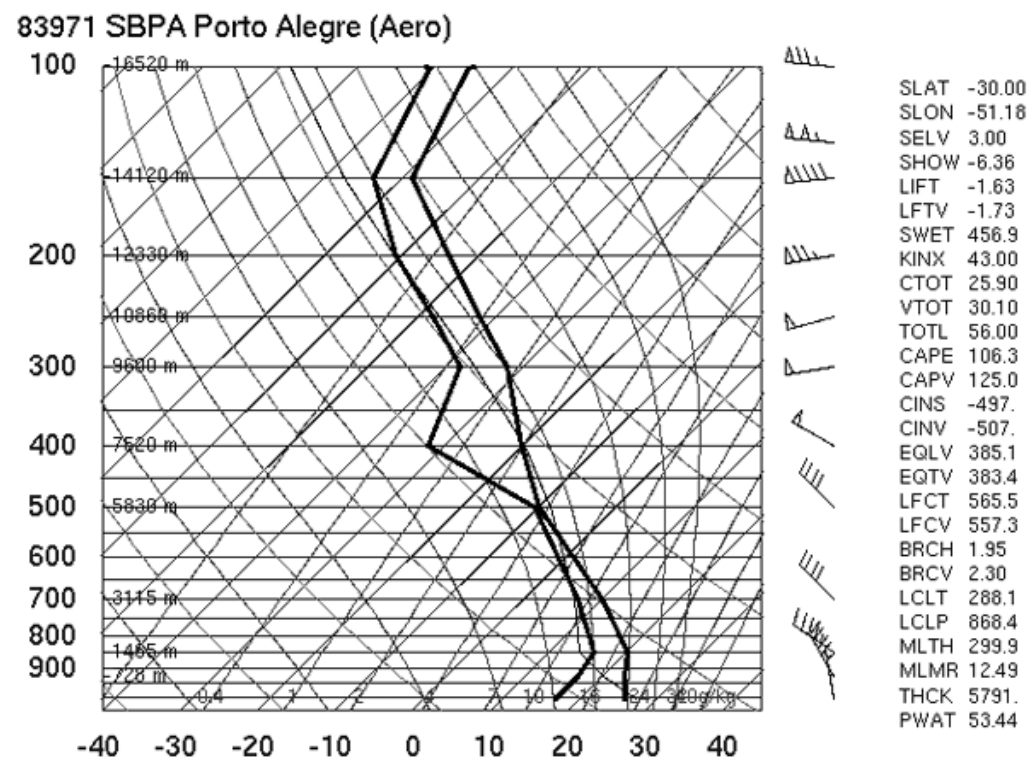

(a) $12211 \mathrm{Dec} 2003$

University of Wyoming

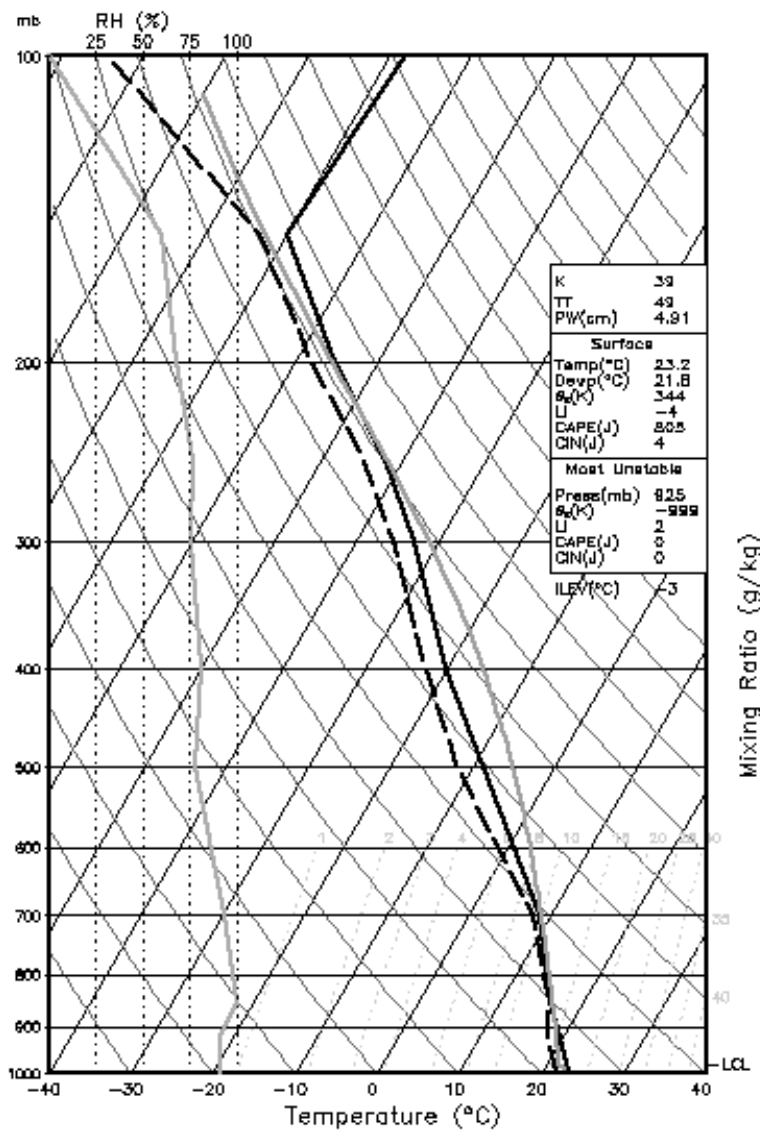

(b)

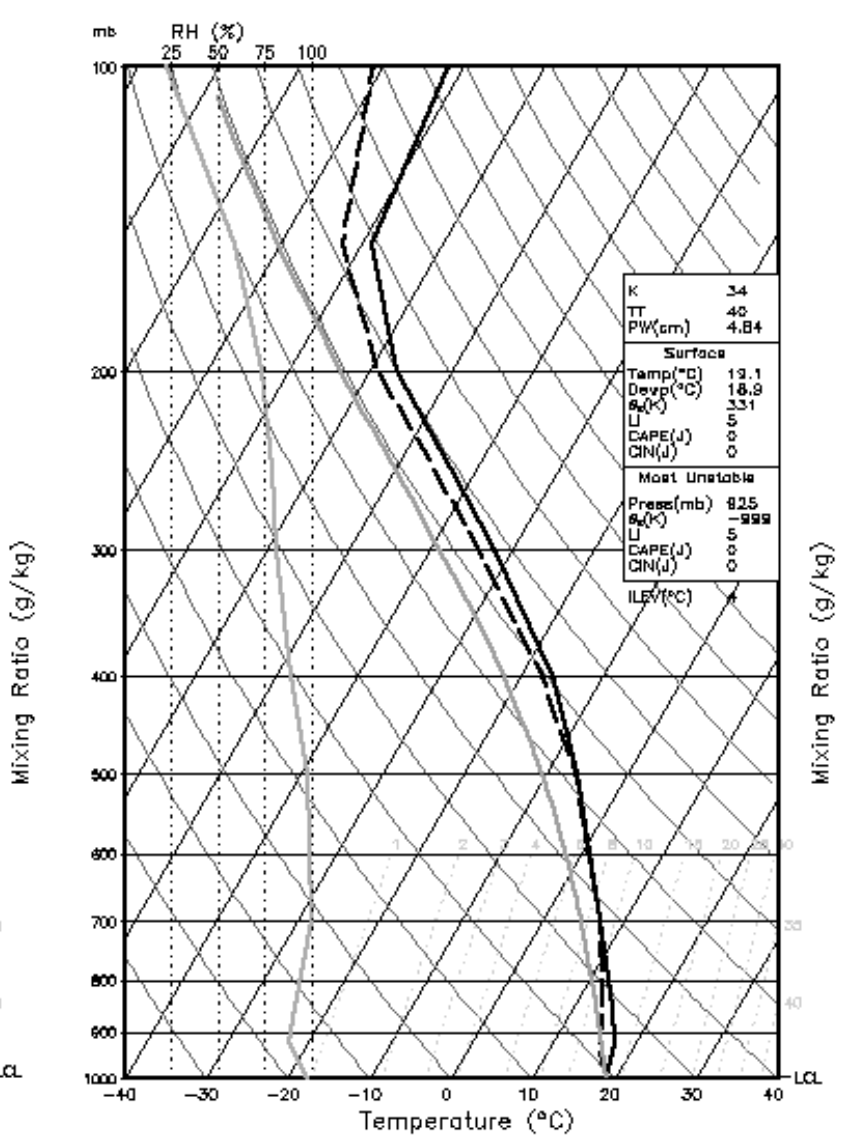

(c)

Figura 7 - Porto Alegre: 12:00 TMG do dia 11/12/2003: (a) Gráfico Skew-T Log observado; (b) Gráfico Skew-T Log-P simulado pelo experimento SCGRELL; (c) Gráfico Skew-T Log-P simulado pelo experimento SCKUO. 


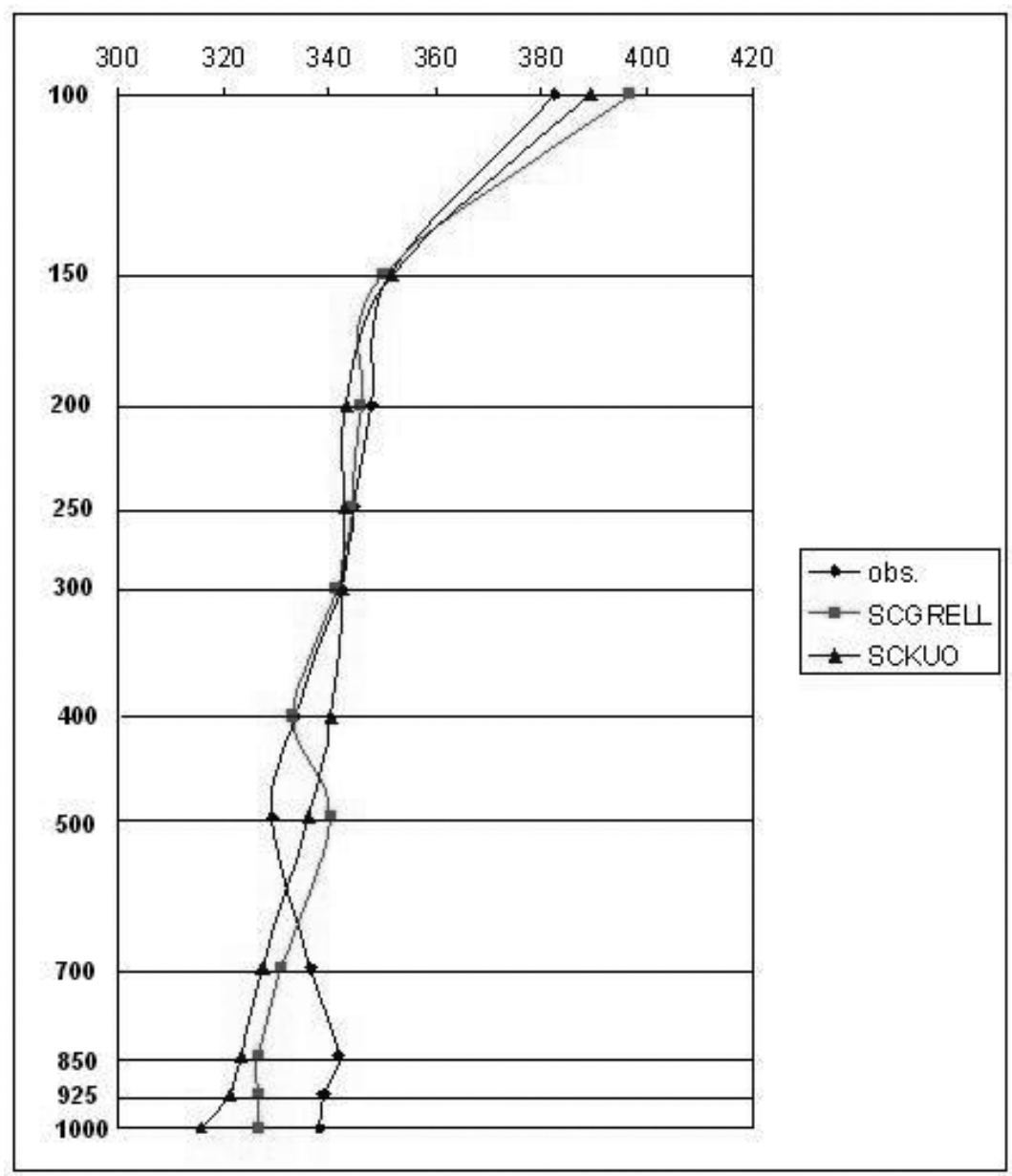

Figura 8 - Porto Alegre: 12:00 TMG do dia 11/12/03: comportamento vertical da temperatura potencial equivalente de saturação $(K)$.

cia a existência de um JBN (Jato de Baixos Níveis) que contribui para 0 acúmulo de umidade e aquecimento do ambiente, trazendo ar quente e úmido das latitudes mais baixas.

Salienta-se que inúmeros trabalhos descrevem a contribuição positiva do JBN no regime pluviométrico na América do sul, com ênfase na região sul do Brasil. Teixeira \& Satyamurty (2004) estudaram as condições sinópticas sazonais associadas a 170 episódios de chuvas intensas na Região Sul do Brasil, ocorridos entre 1991 e 2001, e encontraram uma importante contribuição do escoamento de norte, sobre o Paraguai e nordeste da Argentina, na ocorrência de eventos de chuva intensa na Região Sul do Brasil, através da advecção de grandes quantidades de calor sensível e de umidade. Não obstante, sabe-se que a interação entre os jatos de baixo e alto nível, e a advecção de umidade nas camadas inferiores são fatores importantes quando se discute 0 papel do ambiente na escala convectiva (controle dinâmico).

\section{CARACTERÍSTICAS DA CONVECÇÃO}

Nota-se, observando os perfis médios de aquecimento / resfriamento e umedecimento/secagem convectivos, sobre a região nordeste do Rio Grande do Sul (Fig. 14), que os valores de aquecimento e secagem na média troposfera são bem superiores no experimento SCGRELL, em relação ao SCKUO. Tal perfil evidencia a inclusão dos "downdrafts" (correntes descendentes) no esquema de Grell, pois o principal papel dessas correntes úmidas é justamente resfriar e umedecer as camadas inferiores. Os perfis indicam uma convecção mais intensa no experimento que utiliza a Parametrização Convectiva de Grell, o que já é esperado, já que um ambiente instável, com forte movimento ascendente, conseqüentemente gera mais fluxo de massa e aquece mais os níveis médios. É importante enfatizar que 0 experimento SCKUO registrou um umedecimento em torno de $400 \mathrm{hPa}$, conforme previsto na formulaçãa de Tremback (1990). Esse efeito deveria 


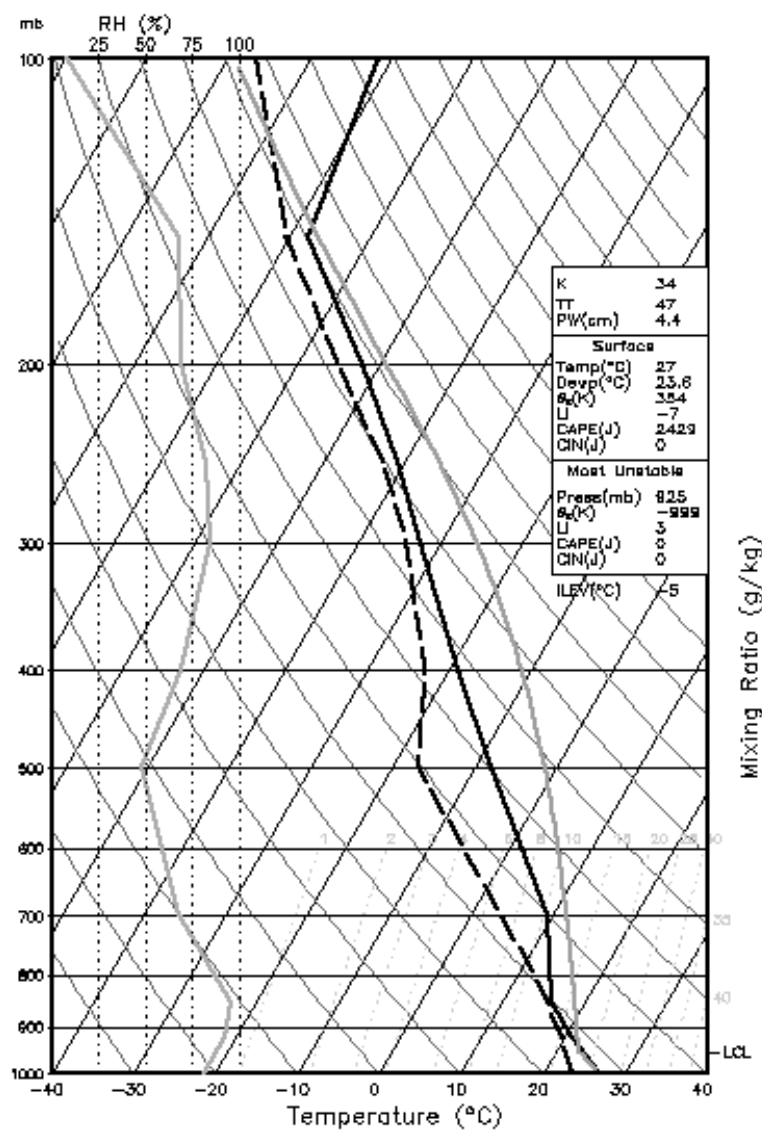

(a)

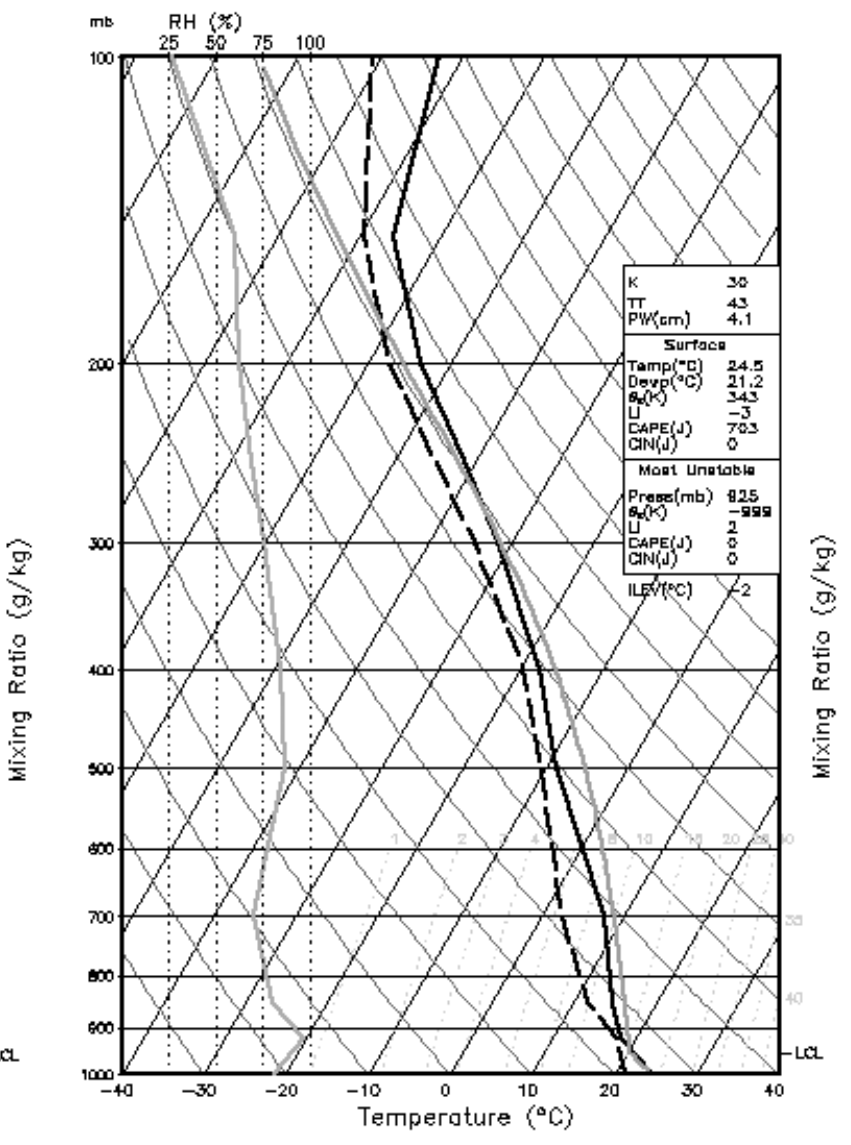

(b)

Figura 9 - Antônio Prado: 18:00 TMG de 11/12/03: Skew-T Log-P simulado em: (a) SCGRELL e (b) SCKUO.

ser observado também no experimento SCGRELL, principalmente devido ao desentranhamento de massa no topo da nuvem.

\section{CONCLUSÕES}

Realizaram-se dois experimentos para testar a atuação das parametrizações convectivas de Grell e de Kuo na simulação de áreas de instabilidade associadas à passagem de uma frente fria sobre 0 estado do Rio Grande do Sul no dia 11 de dezembro de 2003. 0 experimento SCGRELL possui como característica peculiar 0 uso da parametrização convectiva de Grell, e é iniciado com os dados do modelo Global T126L28, fornecidos pelo CPTEC/INPE. 0 experimento SCKUO possui como característica peculiar 0 uso da parametrização convectica de Kuo e também é iniciado com os dados fornecidos pelo CPTEC/INPE.

As comparações entre a intensidade da precipitação simulada e observada e entre 0 ambiente termodinâmico simulado e observado, mostram que a melhor opção de parametrização convectiva, para este caso, foi o esquema de Grell.
A precipitação total acumulada gerada pela Parametrização Convectiva de Kuo subestimou o dado observado, na maior parte do Rio Grande do Sul, e o campo gerado pela Parametrização Convectiva de Grell superestimou 0 dado observado na maioria das regiões gaúchas, porém, foi o mais realístico, em boa parte do estado.

0 ambiente termodinâmico, simulado por SCGRELL às 00:00 e às 12:00 TMG, está mais próximo do dado observado. № horário das 18:00 TMG, o ambiente simulado em SCGRELL apresenta melhores condições de manter tempestades mais severas do que o ambiente simulado em SCKUO. As condições dinâmicas favoráveis para a formação de células convectivas estão presentes na simulação SCGRELL, mostrando que o cisalhamento em baixos níveis e a convergência de umidade contribuíram no bom desempenho da parametrização convectiva de Grell. A presença de um jato de baixos níveis, fenômeno importante na geração e manutenção dos processos convectivos, pôde ser evidenciado em ambas as simulações, o que, sem dúvida, contribuiu na 


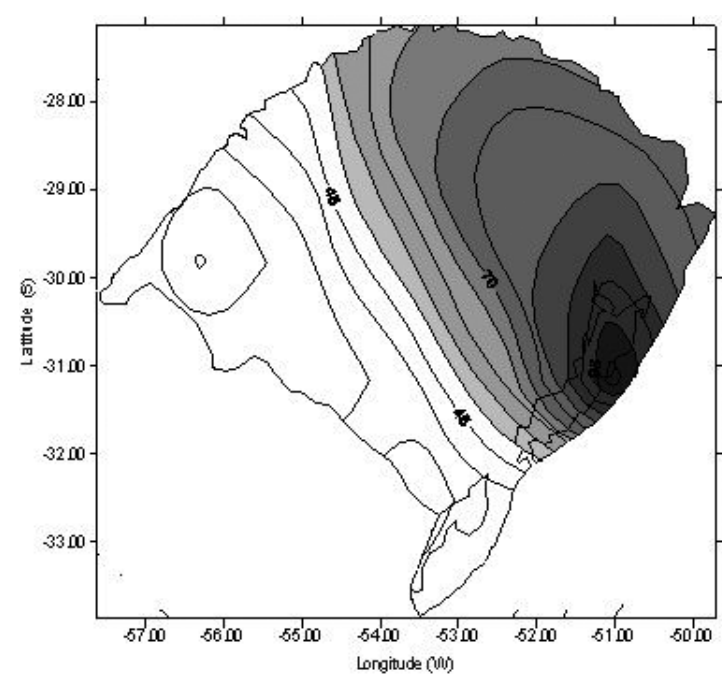

(a)

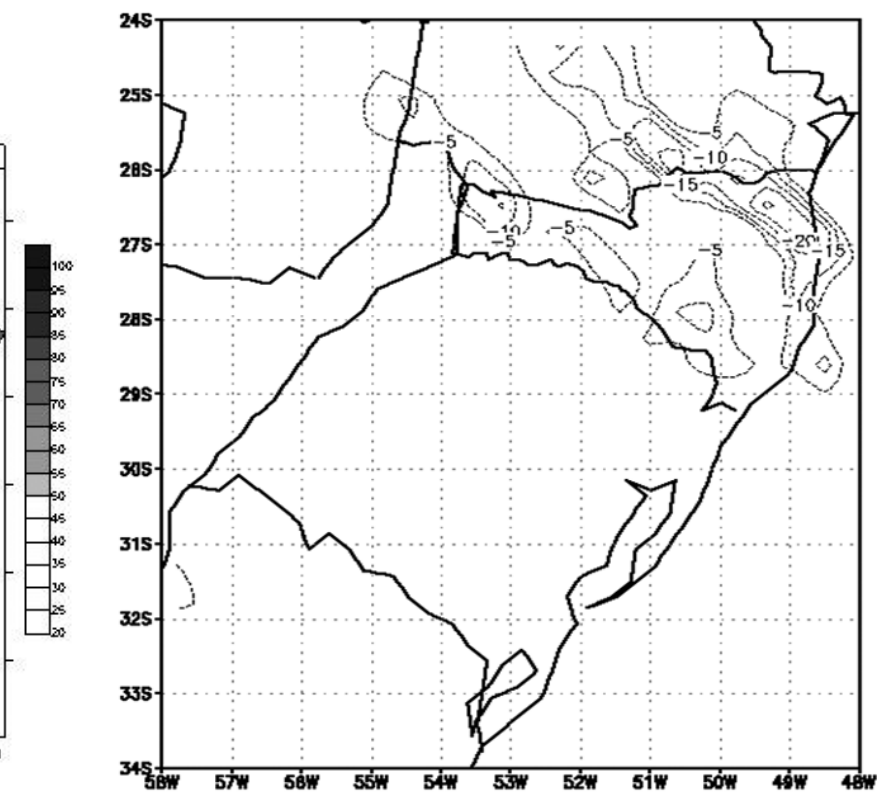

(b)

Figura 10 - 18:00 TMG de 11/12/03: (a) Índice $D N R V$ em $\mathrm{m}^{2} \mathrm{~s}^{-2}$ (a área sombreada corresponde ao intervalo entre 40 e $100 \mathrm{~m}^{2} \mathrm{~s}^{-2}$ ) e (b) convergência de umidade em $\times 10^{-5} \mathrm{~g} . \mathrm{kg}^{-1} . \mathrm{s}^{-1}$ em $1000 \mathrm{hPa}$; simulados em SCGRELL.

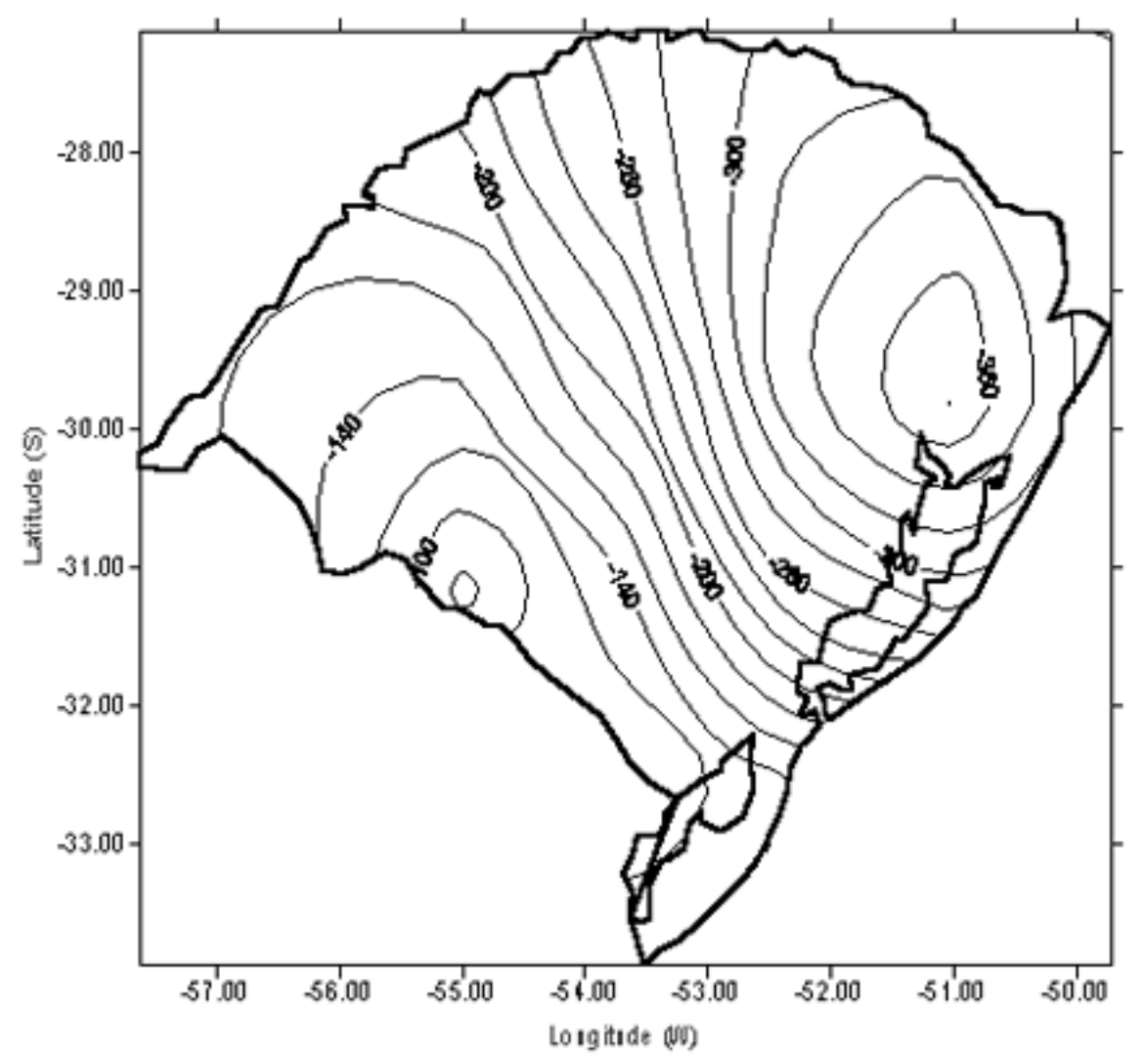

Figura 11 - Campo da Helicidade Relativa para os primeiros $2 \mathrm{~km}$, em $\mathrm{m}^{2} \mathrm{~s}^{-2}$; simulado em SCGRELL. 


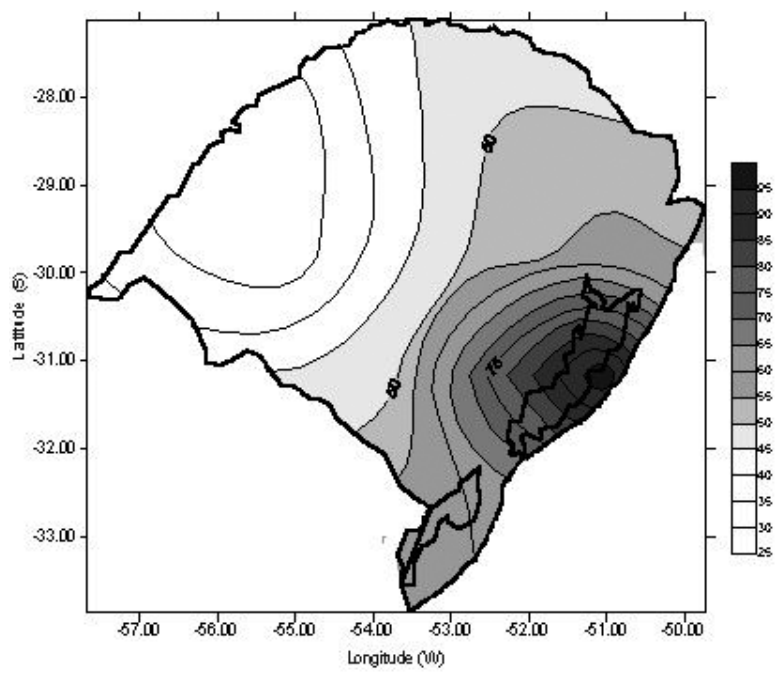

(a)

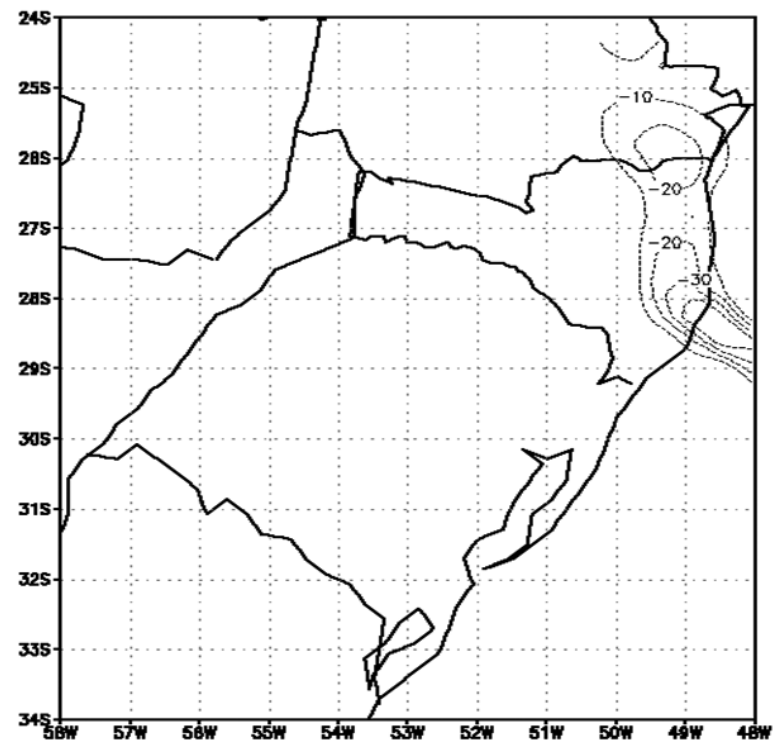

(b)

Figura 12 - 18:00 TMG de 11/12/03: (a) Índice $D N R V$ em $\mathrm{m}^{2} \mathrm{~s}^{-2}$ (a área sombreada corresponde ao intervalo entre 40 e $100 \mathrm{~m}^{2} \mathrm{~s}^{-2}$ ) e (b) convergência de umidade em $\times 10^{-5} \mathrm{~g} \cdot \mathrm{kg}^{-1} . \mathrm{s}^{-1}$, no nível de $1000 \mathrm{hPa}$, simulados em SCKUO.

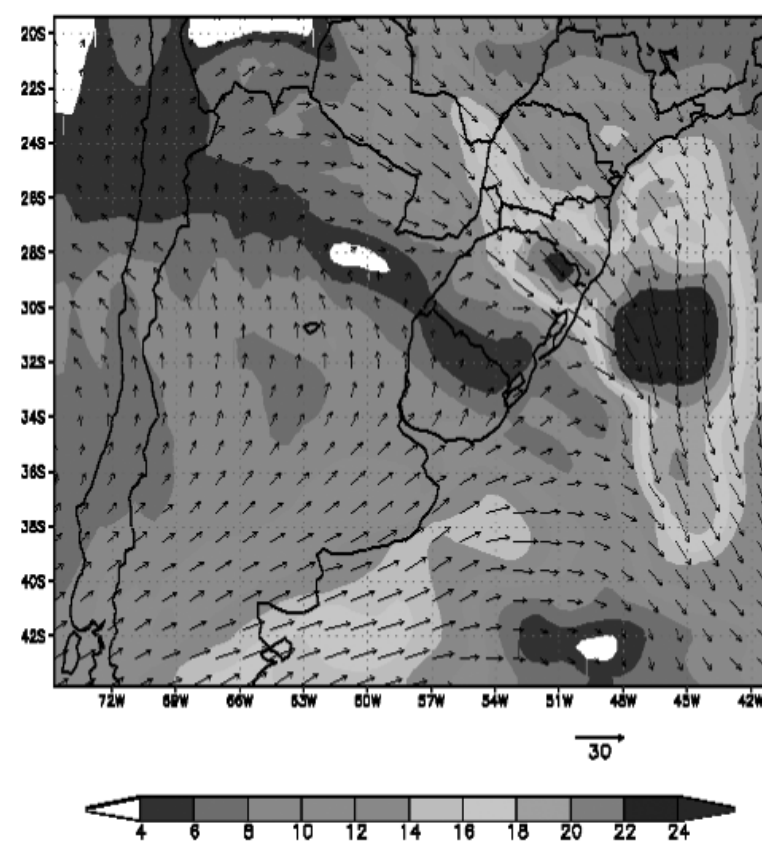

(a)

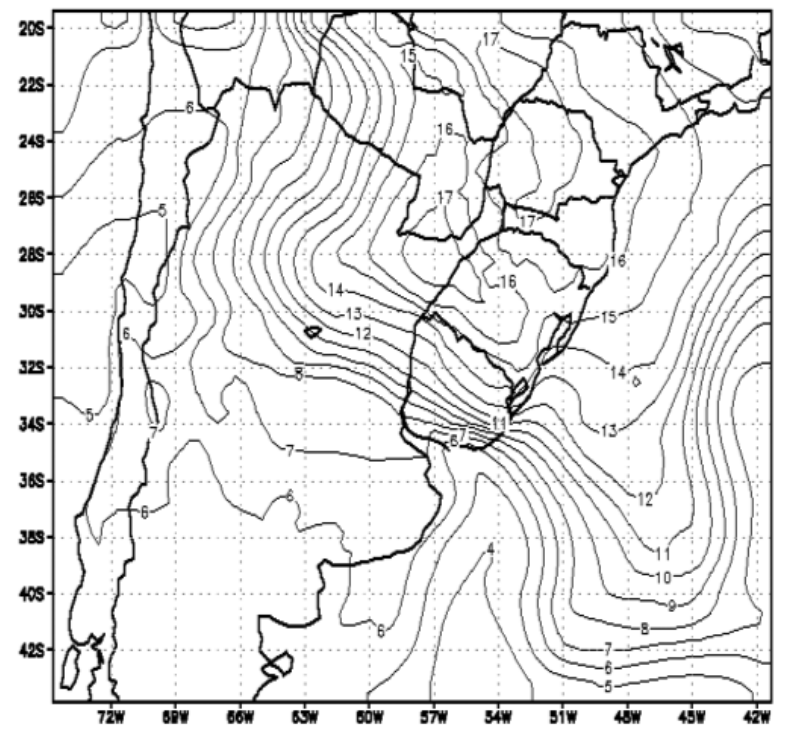

(b)

Figura 13 - 18:00 TMG de 11/12/03: (a) vento (a cor e tamanho dos vetores indicam a intensidade), em $925 \mathrm{hPa}$ e (b) Umidade específica em $925 \mathrm{hPa}$ (g/kg), simulados em SCGRELL. 


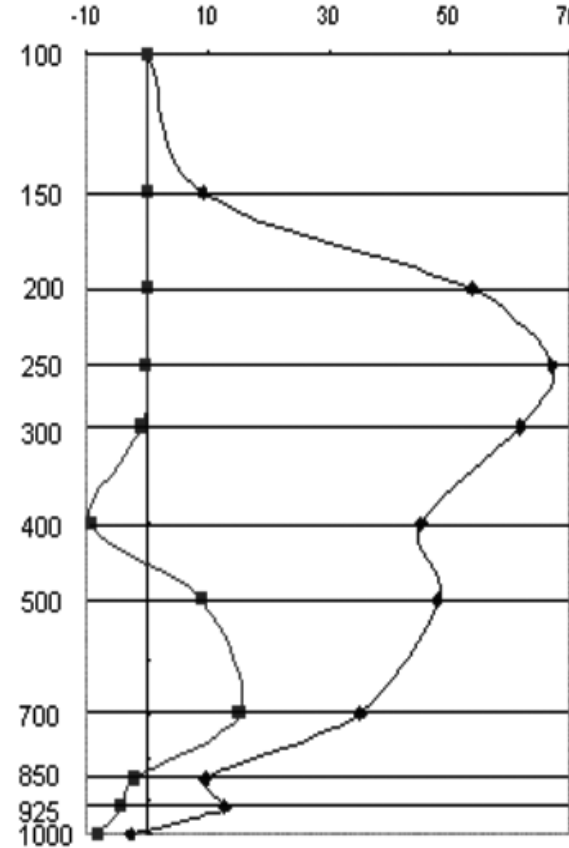

(a)

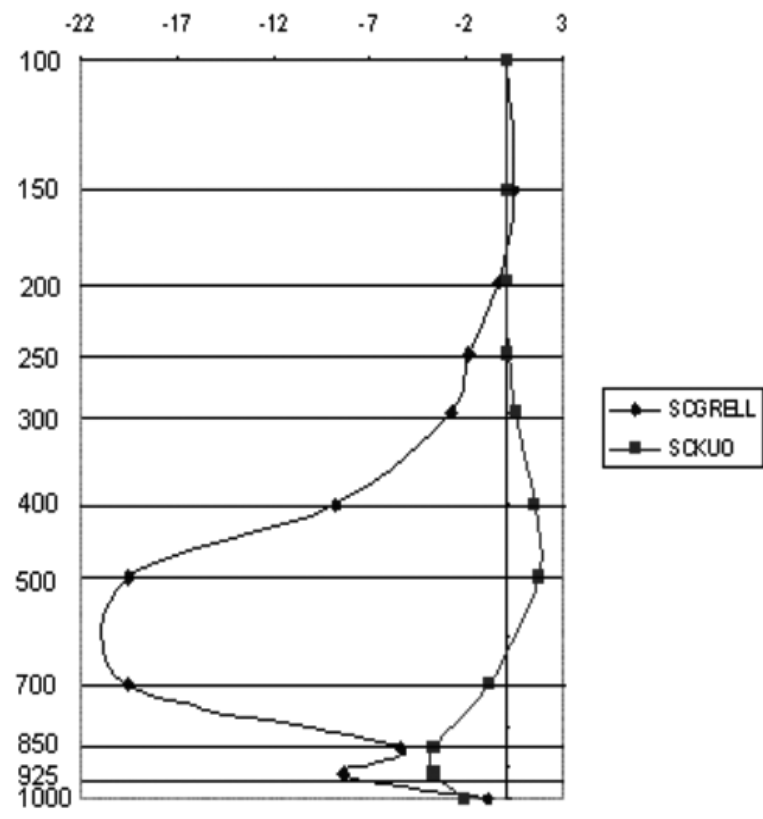

(b)

Figura 14 - 18:00 TMG do dia 17/01/05: Perfis médios de (a) aquecimento/resfriamento e (b) umedecimento/secagem convectivos em K/dia e g/kg/dia, respectivamente.

convecção simulada para a região nordeste do Rio Grande do Sul.

0 alto valor da $C A P E$, valores de helicidade acima de $-150 \mathrm{~m}^{2} \mathrm{~s}^{-2}$ e valores de $D N R V$ entre 40 e $100 \mathrm{~m}^{2} \mathrm{~s}^{-2}$, evidenciaram a possível existência de um tornado em Antônio Prado, às 18:00 TMG. Esse resultado reforça a importância da escolha de um esquema convectivo na aplicação do modelo regional de mesoescala para a previsão de eventos severos ocorridos em território brasileiro.

\section{REFERÊNCIAS}

ALONSO MF, SARAIVA JMB \& FREITAS SR. 2004. Estudo da confiabilidade das simulações do RAMS versão 5.02 (BRAMS) para eventos severos no Rio Grande do Sul. In: Congresso Brasileiro de Meteorologia, 13, Fortaleza. Anais eletrônicos. . Fortaleza: SBMET, 2004. CD-ROM.

ARAKAWA A \& SCHUBERT WH. 1974. Interaction of a cumulus cloud ensemble with the large-scale environment. Part I. J. Atmos. Sci., 31: 674-701.

BOUGEAULT PA. 1985. Simple parameterization of the large-scale effects of cumulus convection. Mon. Wea. Rev., 113: 2108-2121.

COTTON WR \& ANTHES RA. 1989. Storm and Cloud Dynamics. International Geophysics Series, 44 - Academic Press. Inc. 883 pp.
DAVIES JM \& JOHNS RH. 1993. Some wind and instability parameters associated with strong and violent tornadoes. Part I: Wind shear and helicity. In: The Tornado: Its Structure, Dynamics, Prediction and Hazards. Amer. Geophys. Union Geophysical Monograph, 79: 573-582.

DAVIES-JONES R, BURGESS D \& FOSTER MD. 1990. Test of helicity as a tornado forecast parameter. In: Preprints, $16^{\text {th }}$ Conf. Severe Local Storms, Kananaskis Park, Canada. Amer. Met. Soc., p. 588-592.

FINLEY CA, COTTON WR \& PIELKE A. 2001. Numerical simulation of tornadogenesis in a high-precipitation supercell. Part l: Storm evolution and transition into a Bow Echo. J Atmos Sci., 58(13): 1597-1629.

FRITSCH JM. 1975. Cumulus dynamics: Local compensating subsidence and its implications for cumulus parameterization. Pure Appl. Geophys., 13: 851-867.

FRITSCH JM \& CHAPPELL CF. 1980. Numerical prediction of convectively driven mesoscale pressure systems. Part I: Convective Parameterization. J. Atmos. Sci., 37: 1734-1762.

GEVAERD R \& FREITAS SR. 2003. Determinação operacional da umidade do solo para assimilação em modelos de previsão numérica do tempo. In: Simpósio Internacional de Iniciação Científica da USP, 11, São Carlos. Anais eletrônicos. . . São Carlos: USP, 2003. CD-ROM.

GRELL GA. 1993. Prognostic evaluation of assumptions used by cumuIus parameterization. Mon. Wea. Rev., 121: 764-783. 
GRELL GA \& DÉVÉNYI D. 2002. A generalized approach to parameterizing convection combining ensemble and data assimilation techniques. Geophysical Research Letters, 29(14): 38.1-38.4.

HUDSON HR. 1971. On the relationship between horizontal moisture convergence and convective cloud formation. J. Appl. Meteorol., 10: 755-762.

KLEMP JB \& WILHELMSON RB. 1978. The simulation of three dimensional convective storm dynamics. J. Atmos. Sci., 35: 1070-1096.

KUO HL. 1974. Further studies of the parameterization of the influence of cumulus convection on large-scale flow. J. Atmos. Sci., 31: 1232-1240.

KUO YH \& ANTHES RA. 1984. Semiprognostic tests of Kuo-type cumulus parameterization schemes in an extratropical convective system. Mon. Wea. Rev., 112: 1498-1509.

LEWIS JM. 1971. Variational subsynoptic analysis with applications to severe local storms. Mon. Weather Rev., 103: 764-778.

MAHRER Y \& PIELKE RA. 1977. A numerical study of the airflow over irregular terrain. Beiträge zur Physik der Atmosphäre, 50: 98-113.

MELLOR GL \& YAMADA T. 1974. A hierarchy of turbulence closure models for planetary boundary layers. J. Atmos. Sci., 31: 1791-1806.

MELLOR GL \& YAMADA T. 1982. Development of a turbulence closure model for geophysical fluid problems. Rev. Geophys. Space Phys., 20: 851-875.
MENEZES WF. 1998. Tempestades Severas: um modelo para latitudes subtropicais. Tese (Doutorado em Meteorologia) - Universidade de São Paulo, $174 \mathrm{p}$.

NASCIMENTO EL. 2005. Previsão de tempestades severas utilizando-se parâmetros convectivos e modelos de mesoescala: uma estratégia operacional adotável no Brasil? Rev. Bras. Meteor., 20(1): 113-122.

NECHET D. 2002. Ocorrência de tornados no Brasil. Bol. Soc. Bras. Meteor., 26(2): 29-39.

PIELKE RA \& MAHRER Y. 1978. Verification analysis of the University of Virginia three-dimensional mesoscale model prediction over South Florida for 1 July 1973. Mon. Wea. Rev., 106: 1568-1589.

SASAKI Y \& LEWIS JM. 1970. Numerical variational objective analysis of the planetary boundary layer in conjunction with squall line formation. J. Meteorol. Soc. Jpn., 48: 271-381.

TEIXEIRA MS \& SATYAMURTY P. 2004. Episódios de chuvas intensas na região sul do Brasil. Parte l: configurações sinópticas associadas. In: Congresso Brasileiro de Meteorologia, 13, Fortaleza. Anais eletrônicos. . . Fortaleza: SBMET, 2004. CD-ROM.

TREMBACK CJ. 1990. Numerical Simulation of a Mesoscale Convective Complex: Model development and numerical results. Ph.D. Dissertation, Atmos. Sci. Paper n. 465, Colorado State University, 247 p.

\section{NOTAS SOBRE OS AUTORES}

Marcelo Félix Alonso. Possui graduação em Meteorologia pela Universidade Federal de Pelotas (2003) e mestrado em Meteorologia pela Universidade Federal de Pelotas (2006). Atualmente está cursando o curso de doutorado em Meteorologia no Instituto Nacional de Pesquisas Espaciais. Tem experiência na área de Geociências, com ênfase em Meteorologia, atuando principalmente nos seguintes temas: refratividade, modelo BRAMS, parametrização convectiva e previsão do tempo químico.

Jaci Maria Bilhalva Saraiva. Possui graduação em Meteorologia pela Universidade Federal de Pelotas (1986) e doutorado em Meteorologia pela Universidade de São Paulo (1996). Atualmente é professora associada da Fundação Universidade Federal do Rio Grande, Assessora do Sistema de Proteção da Amazônia e professora colaboradora da pós-graduação da Universidade Federal do Amazonas. Tem experiência na área de Geociências, com ênfase em Meteorologia. Atuando principalmente nos seguintes temas: fluxos superficiais de calor latente e sensível, instabilidade baroclínica, ciclogenese. 